\title{
A review of Bennelongia De Deckker \& McKenzie, 1981 (Crustacea, Ostracoda) species from eastern Australia with the description of three new species
}

\author{
Rylan SHEARN ${ }^{1}$, Annette KOENDERS ${ }^{2}$, Stuart HALSE ${ }^{3}$, Isa SCHÖN ${ }^{4}$ \\ and Koen MARTENS ${ }^{5}$ \\ ${ }^{1,2}$ Centre for Ecosystem Management, Edith Cowan University, 270 Joondalup Dv, \\ Joondalup, WA 6027, Australia (corresponding author). \\ Email: rshearn@our.ecu.edu.au \\ ${ }^{3}$ Bennelongia Environmental Consultants, 5 Bishop Street, Jolimont WA 6014, Australia. \\ ${ }^{4,5}$ Royal Belgian Institute of Natural Sciences, Freshwater Biology, \\ Vautierstraat 29, B-1000 Brussels, Belgium. \\ ${ }^{4}$ University of Hasselt, Research Group Zoology, Agoralaan Building D, \\ B-3590 Diepenbeek, Belgium. \\ ${ }^{5}$ University of Ghent, Department of Biology, K.L. Ledeganckstraat 35, B-9000 Ghent, Belgium. \\ ${ }^{1}$ urn:1sid:zoobank.org:author:1145E762-2FED-49B9-942D-42058B4E323E \\ 2 urn:lsid:zoobank.org:author:C10715C9-96BC-4FE1-9B5D-8E4717BF0E8A \\ ${ }^{3}$ urn:1sid:zoobank.org:author:676014BF-5979-49EC-BC8F-811214170111 \\ ${ }^{4}$ urn:1sid:zoobank.org:author:94232F10-7092-4E90-9071-64C4FDABE691 \\ ${ }^{5}$ urn:1sid:zoobank.org:author:9272757B-A9E5-4C94-B28D-F5EFF32AADC7
}

\begin{abstract}
Australia is predicted to have a high number of currently undescribed ostracod taxa. The genus Bennelongia De Deckker \& McKenzie, 1981 (Crustacea, Ostracoda) occurs in Australia and New Zealand, and has recently shown potential for high speciosity, after the description of nine new species from Western Australia. Here, we focus on Bennelongia from eastern Australia, with the objectives of exploring likely habitats for undiscovered species, genetically characterising published morphological species and scanning classical species for cryptic diversity. Two traditional (morphological) species are confirmed to be valid using molecular evidence (B. harpago De Deckker \& McKenzie, 1981 and $B$. pinpi De Deckker, 1981), while three new species are described using both morphological and molecular evidence. Two of the new species belong to the B. barangaroo lineage (B. dedeckkeri sp. nov. and $B$. mckenziei sp. nov.), while the third is a member of the $B$. nimala lineage (B. regina sp. nov.). Another species was found to be genetically distinct, but is not formally described here owing to a lack of distinguishing morphological features from the existing species B. cuensis Martens et al., 2012. Trends in diversity and radiation of the genus are discussed, as well as implications these results have for the conservation of temporary pool microfauna and our understanding of Bennelongia's evolutionary origin.
\end{abstract}

Keywords. Evolution, cryptic species, biodiversity, Queensland, New South Wales.

Shearn R., Koenders A., Halse S., Schön I. \& Martens K. 2012. A review of Bennelongia De Deckker \& McKenzie, 1981 (Crustacea, Ostracoda) species from eastern Australia with the description of three new species. European Journal of Taxonomy 25: 1-35. http://dx.doi.org/10.5852/ejt.2012.25 


\section{Introduction}

Many regions of the earth have been flagged as having poorly documented diversity for inland aquatic crustaceans, such as the Nearctic and Neotropic Amphipoda (Väinölä et al. 2008) or the African and South American Ostracoda (Martens et al. 2008). For each case this can be due either to a low diversity in the region, or to the fact that the region is understudied. In the latter case, taxonomic explorations and scans for cryptic diversity tend to yield a high number of new taxa. Two of the most remarkable cryptic diversity case studies have come from crustaceans. Over 30 cryptic lineages of the amphipod Hyalella azteca (Saussure, 1858) were discovered in desert springs of the USA (Witt et al. 2006), while over 35 cryptic species were found in European (Bode et al. 2010) and Australian (Koenders et al. 2012) populations of the ostracod Eucypris virens Jurine, 1820.

With discoveries of cryptic diversity on the rise and a historically low sampling effort, Australia is a region predicted to have a high number of species awaiting description for several crustacean groups (Martens et al. 2008; Väinölä et al. 2008). Already a high number of copepod (T. Karanovic 2004), branchiopod (Timms 2012) and ostracod (I. Karanovic 2007) species have been found in previously unexplored habitats of Australia, while a high number of cryptic lineages have been identified in desert spring amphipods of inland Australia (Murphy et al. 2009) and freshwater shrimps of eastern Australia (Cook et al. 2006).

Bennelongia De Deckker \& McKenzie, 1981, an ostracod genus occurring in Australia and New Zealand, has shown a similar potential for high speciosity. Recent molecular and morphological work in Western Australia (Martens et al. 2012) revealed that some traditional (morphological) species (De Deckker 1981) consisted of species complexes, while unexplored regions yielded several new (morphological) species.

Several Bennelongia species were originally described from eastern Australia (De Deckker 1981, 1982; De Deckker \& McKenzie 1981). Since then, taxonomically important micro scale characters have been established for the genus (Martens et al. 2012). One of these (the anteroventral lapel on the right valve) has enabled the recognition of several visibly discernible types within one traditional eastern Australian species (see figures 7 and 9 in De Deckker 1981) which suggests that described species of this region may in fact consist of larger species complexes. Furthermore, eastern Australia has many habitats with high aquatic crustacean diversity (Timms \& Sanders 2002) that have not yet been explored for Bennelongia.

The aims of the present study were to sample known and unexplored Bennelongia populations of eastern Australia, to test the validity of traditional (morphological) species using molecular techniques, discover new (morphological) species, and determine the potential presence of cryptic species within this genus.

\section{Material and Methods}

\section{Sampling}

In April 2011, several known Bennelongia localities and a range of other wetlands in east Australia, mostly from Queensland, were sampled for ostracods using a $250 \mu \mathrm{m}$ sweep net. Habitats sampled within the wetlands included littoral vegetation and the sediment-water interface. Contents of the net were emptied into a picking tray and ostracods were picked live using $1 \mathrm{ml}$ pipettes for 30 minutes to one hour. Picked specimens were preserved in $100 \%$ ethanol and stored at $4{ }^{\circ} \mathrm{C}$. Samples of one Bennelongia population from Bloodwood Station in New South Wales were donated by Brian Timms. Locations of the populations used in this study are shown in Fig. 1. All examined material including the type material for new species was deposited in the Queensland Museum, Australia (specimen numbers throughout text with 'W' prefix). 


\section{Morphological analysis}

Valves were removed and stored dry in micropalaeontological slides. Soft parts were dissected on flat glass slides in Hydromatrix mounting medium, using two $1 \mu \mathrm{m}$ diameter tip tungsten needles to tease individual appendages from the body of the animal, then sealed with a coverslip. Drawings of soft parts were made using a camera lucida on a compound microscope. Valves were illustrated by scanning electron microscopy on a Philips XL30 SEM. Post processing of all images was performed in GIMP v2.6.11 (Kimball et al. 1995).

Although all soft parts were examined, only the male hemipenes and prehensile palps were drawn for the species examined here. Other appendages were typical of the genus and illustration was not useful for identification.

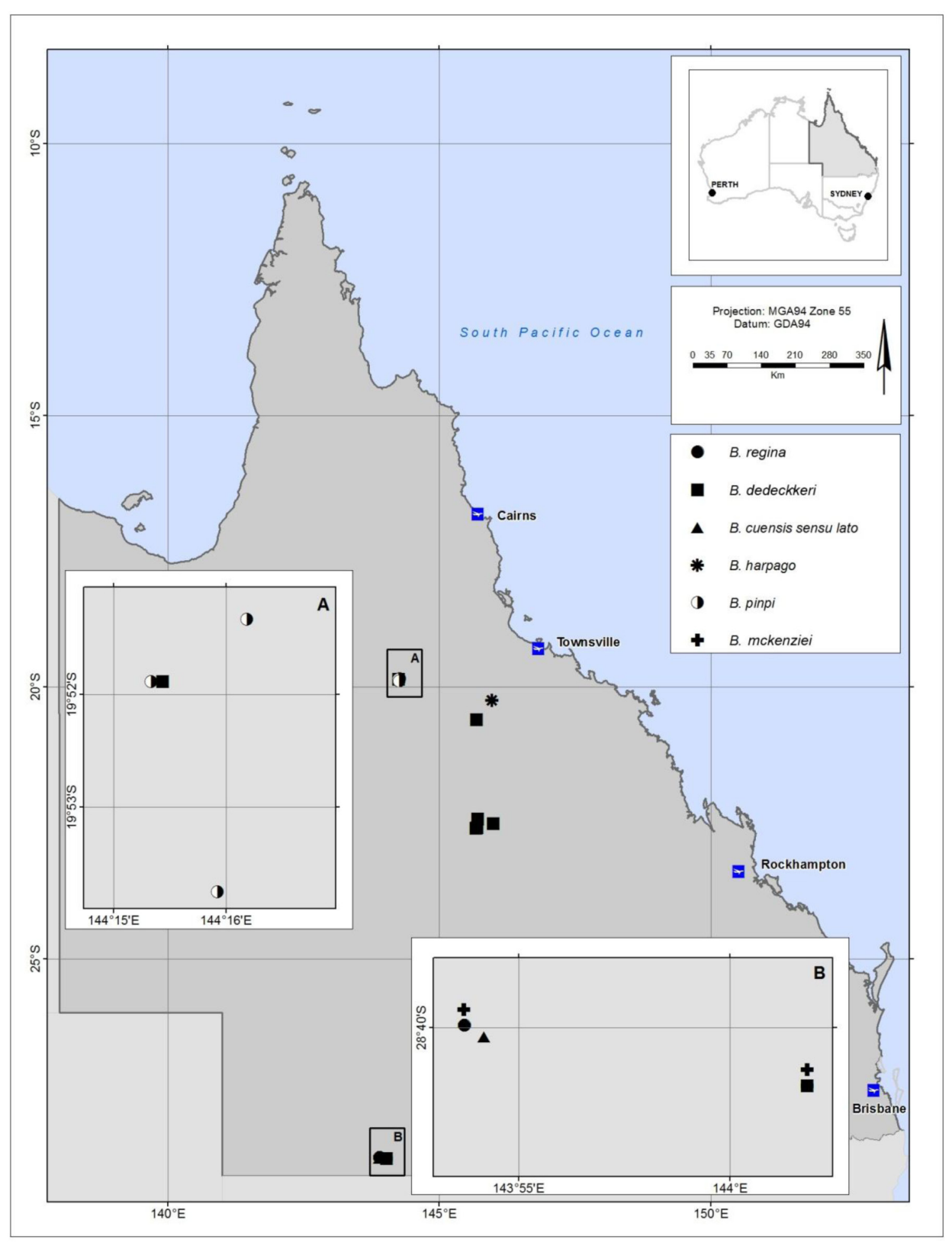

Fig. 1. Map of localities of Bennelongia species from eastern Australia recorded in the present study. 


\section{Molecular analysis}

DNA was extracted from 57 ostracods belonging to 14 populations after their valves were removed and stored in micropalaeontological slides. Soft parts were placed into microcentrifuge tubes with $100 \%$ ethanol. The soft parts were rinsed three times in ultrapure water (100 $\mu 1$ volumes for 10 minutes each rinse), and once in $100 \mu 1$ of $1 \mathrm{x}$ PBS for 10 minutes.

The Qiagen DNeasy blood and tissue kit was used to extract DNA following the manufacturer's protocol. Concentrations of extracted DNA were estimated with a nanodrop spectrophotometer. The highest quality DNA eluate was used for PCR amplification of the 'Folmer' region of the mitochondrial COI gene using universal primers (Folmer et al. 1994), or where this was unsuccessful, alternative primers for mt COI. For PCR amplification, the Qiagen Hotstar mastermix was used, with 3-5 $\mu 1$ of DNA template and 0.1 $\mu \mathrm{M}$ of each primer in a total PCR volume of $25 \mu \mathrm{l}$. Cycling was performed in a BioRad thermocyclers with an initial denaturation temperature of $95^{\circ} \mathrm{C}$ for $15 \mathrm{~min}$, followed by 40 cycles with one minute at $95^{\circ} \mathrm{C}$, one minute at $50^{\circ} \mathrm{C}$, two minutes at $72^{\circ} \mathrm{C}$ and a final 10 minute extension step at $72^{\circ} \mathrm{C}$. Success of PCR amplifications was verified by agarose gel electrophoresis and subsequent Gelred or SybrSafe staining. Successful PCR products were purified with the GFX ${ }^{\mathrm{TM}}$ PCR DNA and gel band purification kit (GE Healthcare) according to the manufacturer's protocol, then sequenced automatically and directly in both directions with the PCR primers and the Big dye kit (ABI) on an ABI 3130X.

\section{Sequence data analysis}

Sequence chromatograms were viewed in FinchTV (Geospiza Inc., n.d.) and, when present, discrepancies were corrected by manually checking sequence chromatograms. The identity of the obtained sequences was confirmed in Genbank using BLAST searches (Altschul et al. 1990).

One final consensus sequence per individual was obtained. These sequences were aligned and trimmed to equal length in ClustalX (Larkin et al. 2007), together with 26 sequences from already described Bennelongia species and one outgroup sequence from the closely related genus Heterocypris (identified throughout the text as Heterocypris spec.). jModelTest (Posada 2008) was used to identify the optimal model of molecular sequence evolution. Phylogenetic reconstructions were conducted with two different methods, Bayesian Inference (BI) was applied using MrBayes 3.1.2 (Huelsenbeck \& Ronquist 2001; with 2,000,000 generations, a burnin of 10,000 and the Bayesian Information Criterion identified by jModeltest for 24 models), and Maximum Likelihood (ML) in PhyML (Guindon \& Gascuel 2003; with 1,000 bootstrap replicates and the Akaike Information Criterion identified by jModeltest for 88 models). Genetic relationships within and between populations were resolved in parsimonious networks constructed at the 95\% probability limit using TCS 1.21 (Clement et al. 2000). Unconnected networks were considered as different genetic species as suggested by Hart \& Sunday (2007). DNA sequences for each species have been submitted to Genbank (accession numbers JX896642-JX896647).

\section{DNA identification of species}

The Evolutionary Genetic species concept (Birky \& Barraclough 2009) was applied using the $4 \mathrm{x}$ rule (Birky et al. 2010) to confirm morphological species boundaries and to detect cryptic species. The $4 \mathrm{x}$ rule was applied as described by Birky et al. (2010) and Schön et al. (2012) by first identifying wellsupported, phylogenetic sister clades and then estimating mean sequence diversities within and pairwise distances between clades with MEGA 5.0 using 1,000 bootstraps (Tamura et al. 2011).

The mean pairwise distance $D$ between sister clades was compared to the population estimate of clade nucleotide diversity $\theta$. Where mean pairwise distances between sister clades $D$ were at least 4 to 4.3 times (depending on the sample size of the clades) greater than the population estimate of clade nucleotide diversity $\theta$ within these clades, this was considered as evidence that the clades were 
different species according to the Evolutionary Genetic species concept (Birky \& Barraclough 2009). Correction of pairwise distances $D$ for multiple hits $K$ was not required, as $D: \theta$ ratios were always well over 4 . Where sister clades were poorly defined in the tree, $D$ values were first estimated to all other potential sister clades in the polytomy, then the clade of lowest $D$ away was considered the sister clade. Although previous analyses may not have clustered these pairs as sister taxa, for the sake of simplicity and readability, clades that have been identified as having the lowest $D$ away will be referred to as 'sister taxa' throughout. Also, in cases where areas of the tree are poorly resolved, it is possible to have many different clades identify a single clade as the shortest pairwise distance $D$ away.

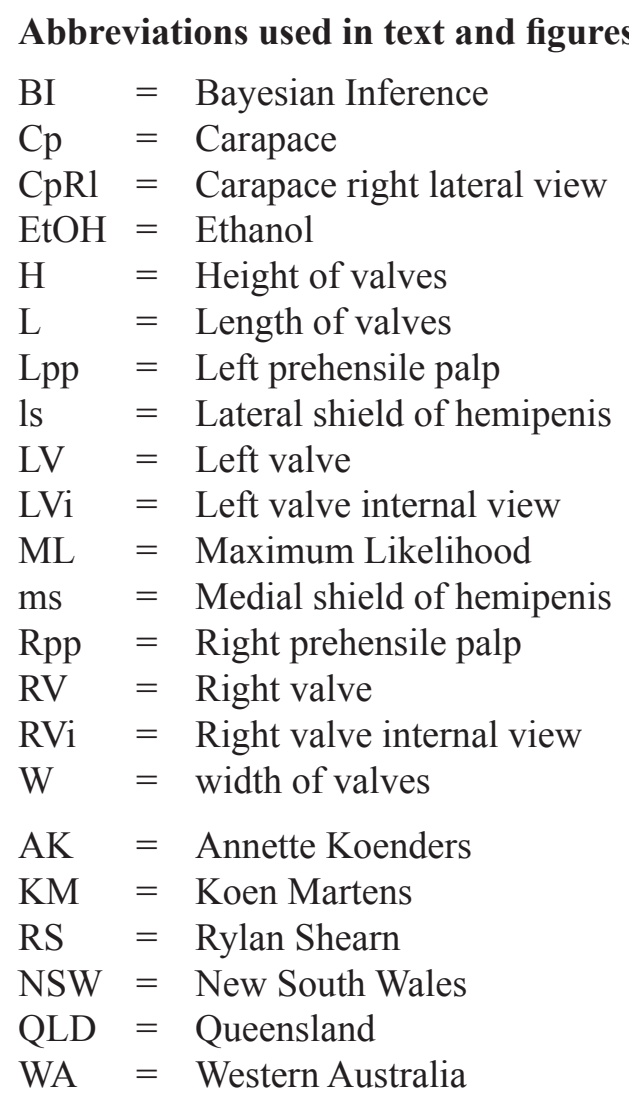

\section{Results}

\section{Results of molecular screening}

$57 \mathrm{COI}$ sequences of $531 \mathrm{bp}$ were obtained from 14 Bennelongia populations throughout Queensland and New South Wales. BLAST searches identified the COI sequences as closely related to other non-marine ostracods. jModeltest selected TPM1 $\mathrm{uf}+\mathrm{I}+\mathrm{G}$ (Kimura 1981) as most appropriate for ML analyses with the following parameters: freqA $=0.3142$, freqC $=0.1855$, freqG $=0.1122$, freqT $=0.3881 ;[\mathrm{AC}]=$ 1.0000, $[\mathrm{AG}]=691.9286,[\mathrm{AT}]=95.0445,[\mathrm{CG}]=95.0445,[\mathrm{CT}]=691.9286,[\mathrm{GT}]=1.0000, \mathrm{p}$-inv $=$ 0.6140 and gamma shape $=2.4420$. The $\mathrm{HKY}+\mathrm{I}+\mathrm{G}$ model (Hasegawa et al. 1985) was chosen as the most appropriate amongst 24 models that could be employed in BI with p-inv $=0.6150$ and gamma shape $=2.0080$.

In both phylogenies, the outgroup (Heterocypris spec.) clustered outside of the Bennelongia lineage (Fig. 2). Both phylogenetic trees contained 12 different Bennelongia clusters with high posterior probabilities and bootstrap support (Fig. 2). Six of these clusters represented Bennelongia species with published COI sequences, namely B. gwelupensis, B. coondinerensis, B. lata, B. cuensis, B strellyensis 


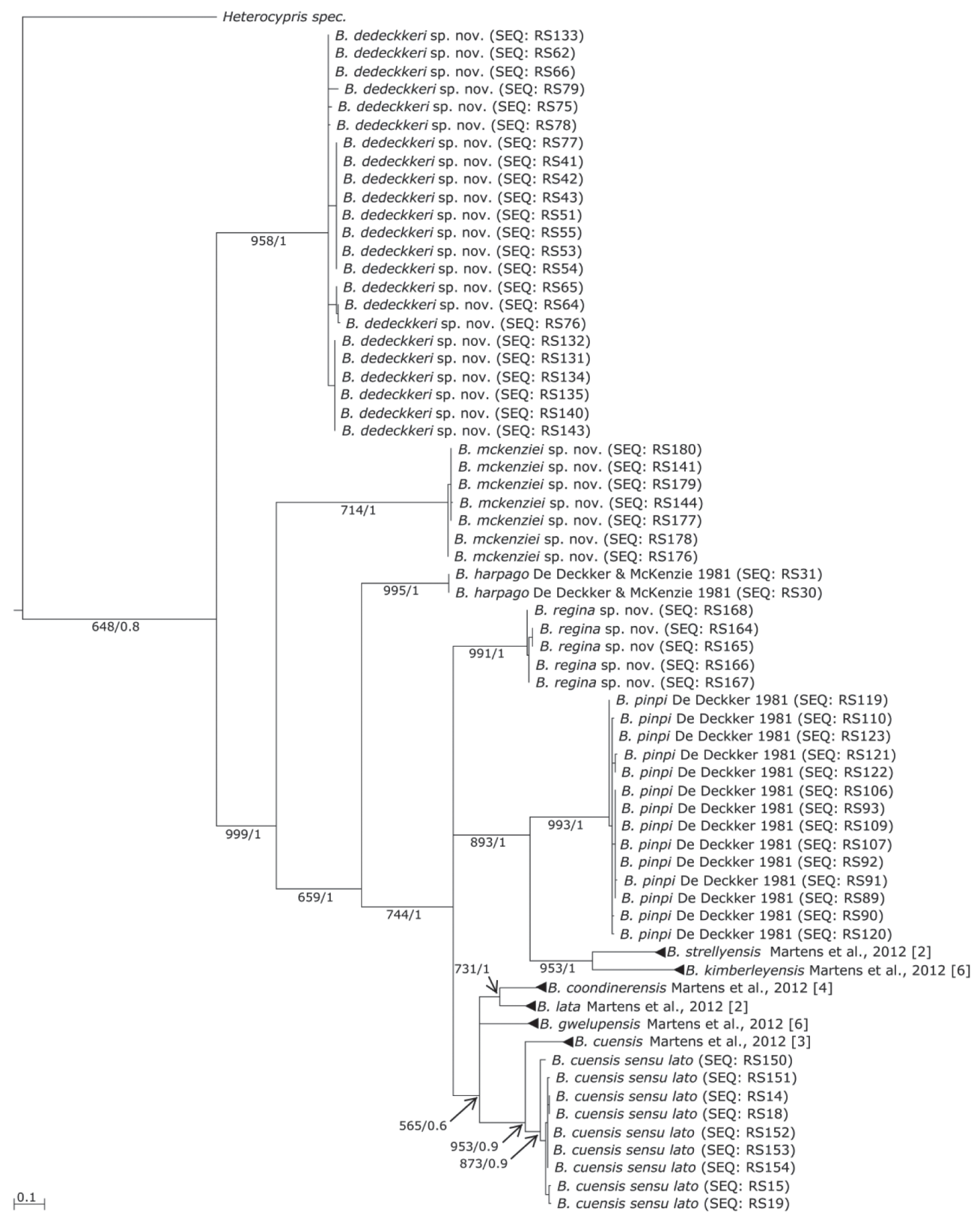

Fig. 2. Phylogenetic tree constructed with 57 novel COI sequences of Bennelongia, 26 published Bennelongia sequences and one Heterocypris spec. as outgroup (sequence names are given in brackets at the end of species names). This tree represents two trees of identical topology inferred by ML and BI. Bootstrap values (for 1000 bootstrap replicates) from ML analyses and Bayesian posterior probabilities (ranging from 0 to 1) are shown for each node (in the format: 'Bootstrap Support/Posterior Probability'). Branch lengths are proportional to the genetic distance scale at the bottom left. Clades with published sequences have been collapsed; the number of sequences in these clades is included in brackets after the species name. Nodes with less than $50 \%$ bootstrap support and a posterior probability of less than 0.5 have been collapsed. The tree shows six strongly supported clades that correspond to the species presented in this study. 

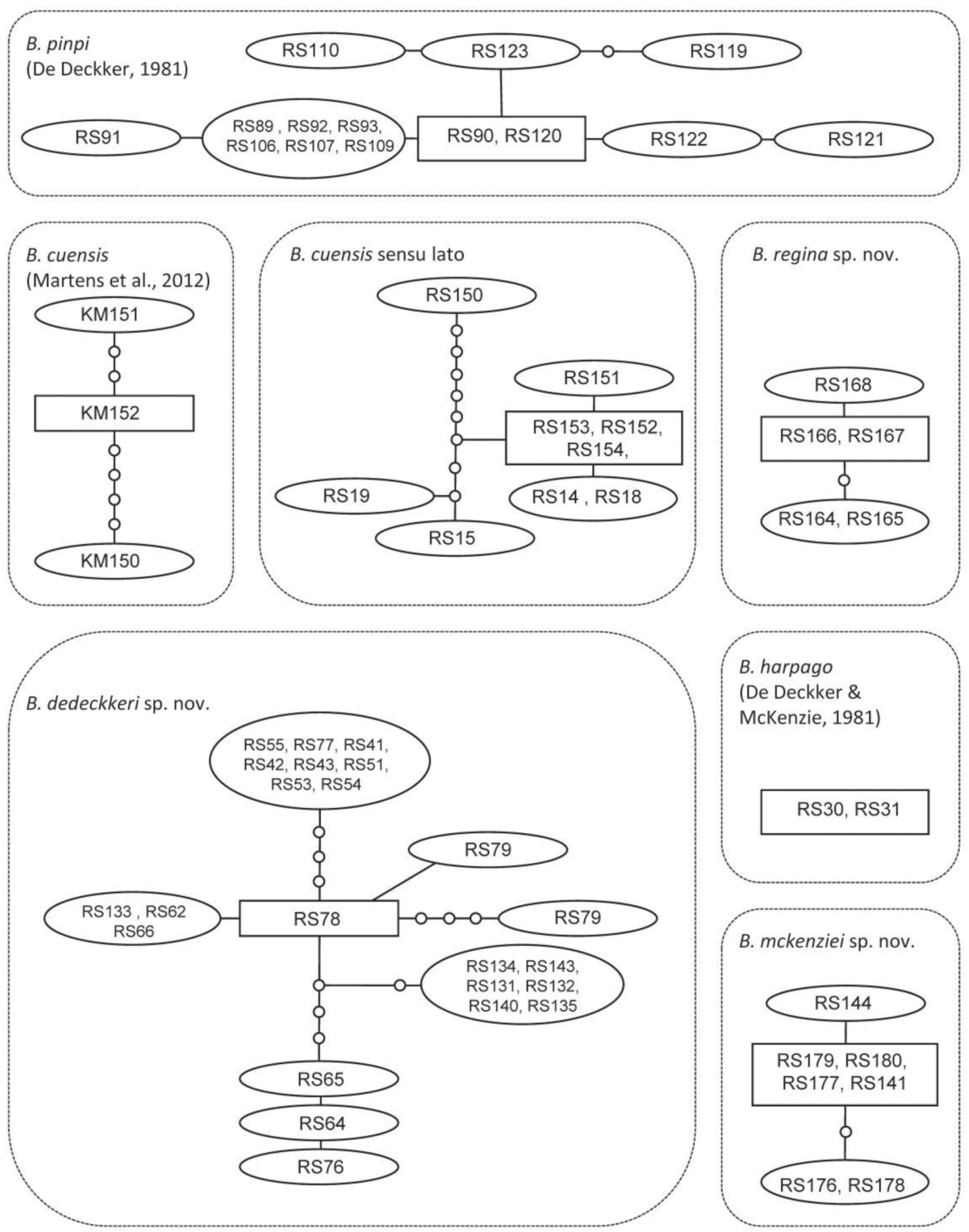

Fig. 3. Parsimonious network constructed at the $95 \%$ probability limit with COI sequences from Bennelongia specimens. For each haplotype, sequence names are given. Squares indicate ancestral haplotypes, small circles missing haplotypes and dotted lines connection boundaries. Only seven of the 12 unconnected networks are shown here, the remaining five were clearly separated from the sequences investigated here and corresponded to the published networks in Martens et al. (2012). Six of the unconnected networks shown here are congruent with the newly described species. One network with previously published sequences (B. cuensis Martens et al., 2012) was included to illustrate its separation to the cryptic species $B$. cuensis sensu lato. 
and B. kimberleyensis (all from Martens et al. 2012, see Fig. 2). Specimens identified in the current study as B. pinpi De Deckker, 1981, B. harpago De Deckker \& McKenzie, 1981 and B. cuensis sensu lato formed their own distinct phylogenetic clusters, as did B. dedeckkeri sp. nov., B. mckenziei sp. nov. and $B$. regina sp. nov. described here as new species (Fig. 2). Bennelongia pinpi formed one larger phylogenetic clade together with B. kimberleyensis Martens et al., 2012 and B. strellyensis Martens et al., 2012 (the B. pinpi lineage) while B. cuensis senu lato grouped with B. cuensis Martens et al., 2012 (Fig. 2). The Bennelongia regina sp. nov. clade (of the $B$. nimala lineage) was formed outside of the $B$. pinpi lineage cluster and the cluster representative of the $B$. australis lineage (B. coondinerensis Martens et al., 2012, B. lata Martens et al., 2012, B. gwelupensis Martens et al., 2012 and B. cuensis Martens et al., 2012). Although the phylogenetic relationships at the higher taxonomic level between the $B$. pinpi, $B$. australis and $B$. nimala lineages could not be resolved, they still belong to the same, distinctive phylogenetic clade with high support (Fig. 2). On the other hand, Bennelongia dedeckkeri sp. nov., B. mckenziei sp. nov. and B. harpago De Deckker \& McKenzie, 1981 formed their own distinct clusters (Fig. 2).

Twelve unconnected parsimonious networks were obtained (Fig. 3), although five of these are not shown as they corresponded to the published networks of Martens et al. (2012). One corresponded to the published network of B. cuensis (Martens et al. 2012) and is shown, as it formed a separate network to the morphologically similar $B$. cuensis sensu lato sp. nov. The two specimens of $B$. harpago De Deckker \& McKenzie, 1981 formed one separate network, as did all specimens of $B$. pinpi De Deckker, 1981 and the three novel species described below, B. regina sp. nov., B. dedeckkeri sp. nov., and B. mckenziei $\mathrm{sp}$. nov., respectively.

Eight different haplotypes were found in the 14 specimens of B. pinpi De Deckker, 1981 (Fig. 3) while the two analysed $B$. harpago De Deckker \& McKenzie, 1981 specimens belonged to one haplotype. Bennelongia regina sp. nov. and $B$. mckenziei sp. nov. were represented by three closely related haplotypes from the five and seven individuals, respectively, that had been investigated. Bennelongia dedeckkeri sp. nov. was the most sampled group with 23 specimens, and also showed the most haplotypes. Of the ten haplotypes, two were especially common. The cryptic $B$. cuensis sensu lato was shown as unconnected to $B$. cuensis Martens et al., 2012. In the nine sequences of B. cuensis sensu lato, one distant and five closely related haplotypes were found.

For the $4 \mathrm{x}$ rule, the B. cuensis sensu lato clade and B. cuensis Martens et al., 2012 clade were identified as sister clades of one another based on the tree topology in Fig. 2. The sister clades for all other novel genetic clades were poorly defined in the tree topology in Fig. 2, so the following sister clades were identified after searching for the lowest $D$ and $K$ to other clades in the polytomy: $B$. dedeckkeri sp. nov. - B. regina sp. nov., B. mckenziei sp. nov. - B. harpago De Deckker \& McKenzie, 1981, B. regina sp. nov. - B. gwelupensis Martens et al., 2012, B. pinpi De Deckker, $1981-B$. strellyensis Martens et al., 2012 and B. harpago De Deckker \& McKenzie, 1981 - B. regina sp. nov. For all pairs of sister clades, mean pairwise distances $D$ between them were more than four times higher than the population estimate for clade nucleotide diversity $\theta$ within these clades (Table 1 ) and ranged from 5 (B. cuensis sensu lato - B. cuensis Martens et al., 2012) to 57.3 times higher (B. mckenziei sp. nov. - B harpago De Deckker \& McKenzie, 1981). 
Table 1. Results from calculations for the $4 x$ rule.

Following the procedure of Birky et al. (2010), ratios of $D$ to $\theta$ are shown for phylogenetic sister clades or the two clades with the lowest mean pairwise distance. In order to fulfil the criteria for the Evolutionary Genetic species concept, this ratio must be equal to or greater than 4 .

$n_{1}=$ number of sequences in first sister clade; $n_{2}=$ number of sequences in second sister clade; Max. $\theta=$ maximum population nucleotide diversity of the two clades; $D=$ mean pairwise distance between each sister clade pair.

\begin{tabular}{|l|c|c|c|c|}
\hline \multicolumn{1}{|c|}{ Sister clades } & $\left(\mathbf{n}_{\mathbf{1}} \mid \mathbf{n}_{\mathbf{2}}\right)$ & Max. $\boldsymbol{\theta}$ & $\boldsymbol{D}$ & $\boldsymbol{D}: \boldsymbol{\theta}$ \\
\hline $\begin{array}{l}\text { B. dedeckkeri sp. nov. - } \\
\text { B. regina sp. nov. }\end{array}$ & $(23 \mid 5)$ & 0.009 & 0.140 & $15.0: 1(D>49)$ \\
\hline $\begin{array}{l}\text { B. } \text { mckenziei sp. nov. - } \\
\text { B. harpago }\end{array}$ & $(7 \mid 2)$ & 0.003 & 0.159 & $57.3: 1(D>49)$ \\
\hline $\begin{array}{l}\text { B. regina sp. nov. - } \\
\text { B. gwelupensis }\end{array}$ & $(5 \mid 6)$ & 0.005 & 0.090 & $17.3: 1(D>49)$ \\
\hline $\begin{array}{l}\text { B. pinpi- } \\
\text { B. strellyensis }\end{array}$ & $(14 \mid 5)$ & 0.004 & 0.140 & $35: 1(D>46)$ \\
\hline $\begin{array}{l}\text { B. harpago - } \\
\text { B. regina } \text { sp. nov. }\end{array}$ & $(2 \mid 5)$ & 0.004 & 0.128 & $33.3: 1(D>49)$ \\
\hline $\begin{array}{l}\text { B. cuensis sensu lato - } \\
\text { B. cuensis }\end{array}$ & $(9 \mid 3)$ & 0.011 & 0.061 & $5.4: 1(D>46)$ \\
\hline
\end{tabular}

Taxonomic descriptions

\author{
Class Ostracoda Latreille, 1806 \\ Subclass Podocopa G. W. Müller, 1894 \\ Order Podocopida G.O. Sars, 1866 \\ Suborder Cypridocopina Baird, 1845 \\ Superfamily Cypridoidea Baird, 1845 \\ Family Cyprididae Baird, 1845 \\ Subfamily Bennelongiinae Martens, Halse \& Schön, 2012 \\ Genus Bennelongia De Deckker \& McKenzie, 1981
}

\title{
Bennelongia barangaroo lineage
}

\section{Remarks}

Bennelongia barangaroo De Deckker, 1981 was originally described from Cauckingburra Swamp (near Lake Buchannan, QLD) and was diagnosed by valve and hemipenes structure (De Deckker 1981). The description included illustrations of specimens from other populations, additional to the type locality, one of which was from a creek bed near Cue in Western Australia (De Deckker 1981). The SEM plates show the type specimen with an obvious anteroventral lapel on the RV, and the specimen from Cue with a reduced or non-existent anteroventral lapel (De Deckker 1981). More recently, a revision of the Western Australian species of the genus Bennelongia established this lapel as an important morphological character at the species level (Martens et al. 2012). Thus, it has become apparent that the population from Cue (De Deckker 1981) was likely to be a different species from the true B. barangaroo of Cauckingburra Swamp. 
Although this finding regarding the specimens from Cue did not change the specific status of $B$. barangaroo, it did bring into question whether the other populations identified in the original description were actually $B$. barangaroo, or whether they were part of a more diverse species complex. Here further evidence is provided for this $B$. barangaroo species complex through the description of two new species within the lineage, both of which are clearly different from $B$. barangaroo and the specimen from Cue illustrated in De Deckker (1981).

The Bennelongia barangaroo lineage consists of three species, B. barangaroo De Deckker, 1981, $B$. dedeckkeri sp. nov. and B. mckenziei sp. nov. They are characterized by a small carapace $(\mathrm{L} \approx 1000$ $\mu \mathrm{m}$, the smallest of all described Bennelongia species). They can be distinguished further from the B. cygnus and B. tunta lineages by the rounded dorsal margin of the Cp (triangular in B. cygnus, rectangular in $B$. tunta), from the $B$. australis lineage by the less pronounced anterior rostrum in dorsal view, from the $B$. pinpi lineage by the less pronounced beak structure of the $\mathrm{LV}$, from the $B$. nimala lineage by the small anteroventral overlap of LV over RV (large overlap in B. nimala) and less elaborate external valve ornamentation and from the $B$. harpago lineage by the absence of an anterodorsal humplike thickening of the LV.

\section{Bennelongia dedeckkeri sp. nov. urn:1sid:zoobank.org:act:E1020EC3-B809-4FDF-876D-822C46A241D6}

Figs 4-5

\section{Diagnosis}

Cp relatively small $(\mathrm{L} \approx 1000 \mu \mathrm{m})$, with similar size and appearance between sexes; in dorsal view with reduced anterior rostrum, blunt posterior and reduced anteroventral overlap of LV over RV; in lateral view with rounded dorsal margin; LV with less developed anteroventral beak-like structure, rounded dorsal margin; RV with straight posterodorsal margin (hinge), greatest height slightly anterior of the middle, short and ventrally pointed anteroventral lapel present; hemipenes with 1s protruding well beyond ms, tips of ls and ms separated, ls distally pointed; distal Rpp segment with pointed dorsal margin, proximal segment with rounded ventral margin and nearly straight dorsal margin; Lpp proximal segment elongated with subapical sensory organ, distal segment sickle shaped, shorter than proximal segment and sharply curved over $180^{\circ}$.

\section{Etymology}

The species is named after Dr P. De Deckker, who described the Bennelongia genus with Dr K. McKenzie in 1981.

\section{Type material}

\section{Holotype}

$\widehat{\delta}$ (W40075), with soft parts dissected in a sealed slide, RV and LV stored dry in a micropalaeontological slide.

\footnotetext{
Allotype

q (W40018), with soft parts dissected in a sealed slide and valves stored dry in a micropalaeontological slide.

\section{Paratypes}

Three $\widehat{\partial}$ carapaces stored in a micropalaeontological slide (W40021-W40023), $3 q$ carapaces stored in a micropalaeontological slide (W40024-W40026), 2 के with soft parts dissected in a sealed slide and valves stored in a micropalaeontological slide (W40016-W40017), $q$ LV stored in a micropalaeontological slide (W40020) and + RV stored in a micropalaeontological slide (W40019).
}

Several in toto specimens in EtOH (W40076). 

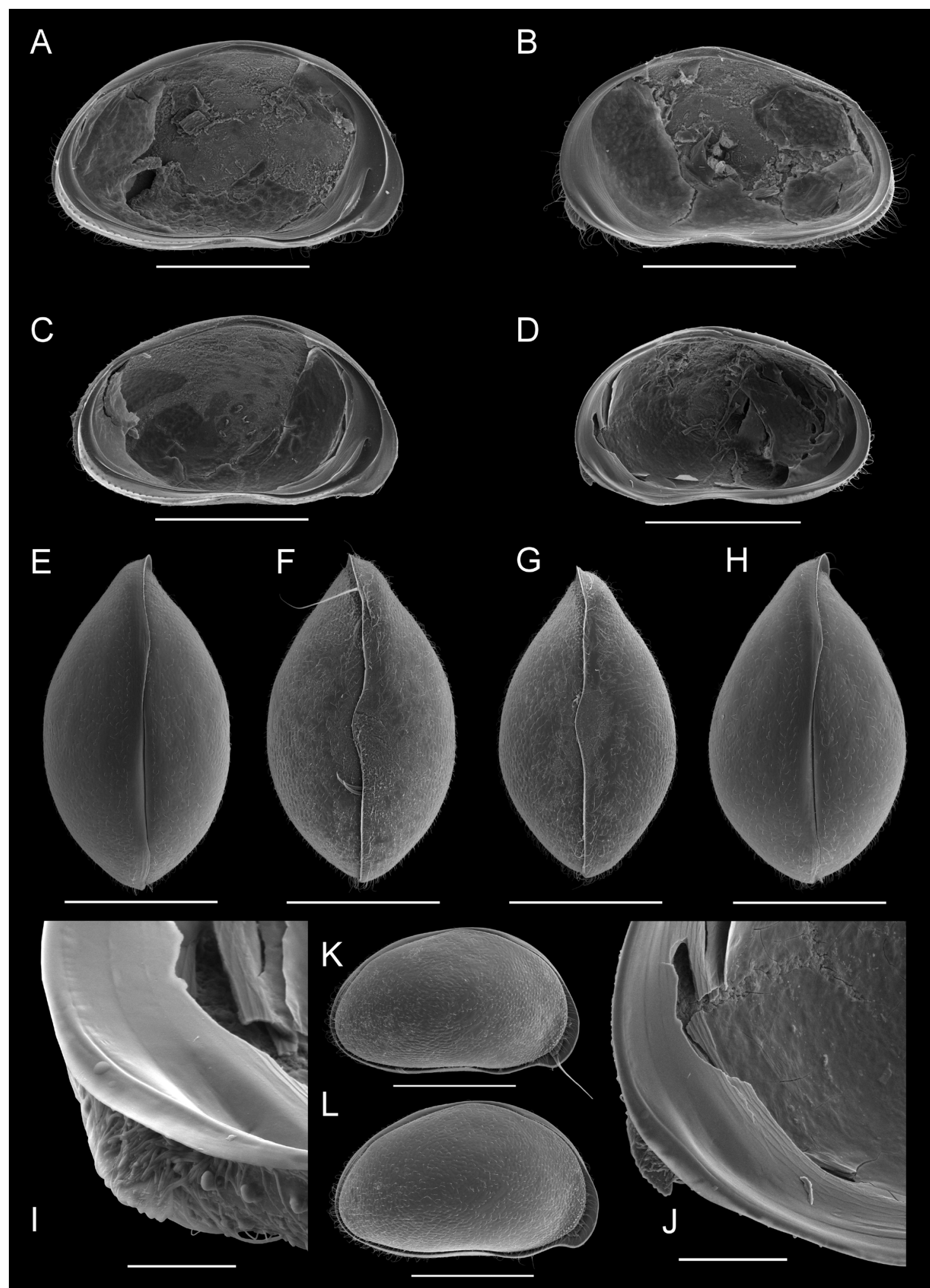

Fig. 4. Bennelongia dedeckkeri sp. nov., all from Lake Galilee, QLD (Type locality). A. \&, LVi (W40020).

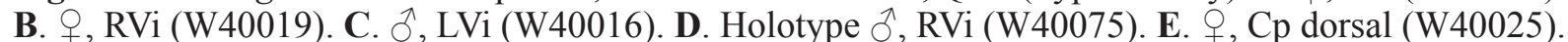
F. + , Cp ventral (W40026). G. $\partial^{\lambda}, \mathrm{Cp}$ (ventral W40023). H. $\partial^{\lambda}, \mathrm{Cp}$ dorsal (W40022). I. Holotype $\hat{\partial}$, RVi detail anteriorly (W40075). J. ô, RVi detail anteriorly (W40019). K. Ô, CpR1 (W40021). L. +, CpR1 (W40024). Scales: A-H, K-L $=500 \mu \mathrm{m}, \mathrm{I}-\mathrm{J}=100 \mu \mathrm{m}$. 


\section{Type locality}

Lake Galilee, south bank, approximately $70 \mathrm{~km}$ north-east of Aramac QLD, coordinates: 22²5'55.4" S $145^{\circ} 42^{\prime} 27.2^{\prime \prime}$ E. Material used for the present description was collected on 07 Jun. 2011 by RS and AK (Sample QLDP9A).

\section{Measurements (in $\mu \mathrm{m}$ )}

ภ. RV: $\mathrm{L}=985-1007(n=2), \mathrm{H}=572-597(n=2) . \mathrm{LV}: \mathrm{L}=1053-1067(n=2), \mathrm{H}=604-625(n=2)$.

Cp: $\mathrm{L}=1010-1082$ ( $n=4), \mathrm{W}=581-644, \mathrm{H}=600-603$. $(n=2)$.

क: $\mathrm{RV}: \mathrm{L}=1099-1150(n=5), \mathrm{H}=663-706(n=5) . \mathrm{LV}: \mathrm{L}=1157-1222(n=5), \mathrm{H}=685-738(n=5)$. Cp: $\mathrm{L}=1078-1224(n=9), \mathrm{W}=613-738(n=4), \mathrm{H}=724-733(n=4)$.

\section{Other material investigated}

Dam near Lake Dunn, north east of Aramac QLD collected by RS and AK on 7 Jun. 2011, coordinates: 22036'15.7" S - 14540'21.3" E (Sample QLDP10A).

Stagnant Channel, near Lake Dunn north east of Aramac QLD collected by RS and AK on 7 Jun. 2011,

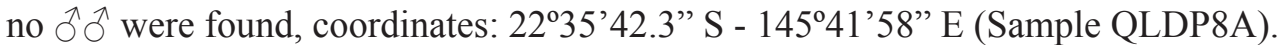

Flooded field, near Lake Dunn north east of Aramac QLD collected by RS and AK on 6 Jun. 2011, no

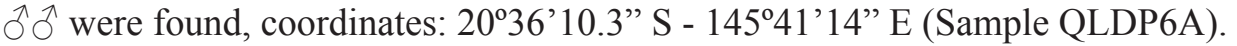

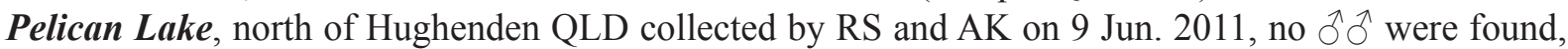
coordinates: 1951'53.1" S - 144¹5'20" E (Sample QLDP13B).

Cardenyabba Lagoon, Kilcowera Station, south of Thargomindah QLD collected by AK on 14 Jun.

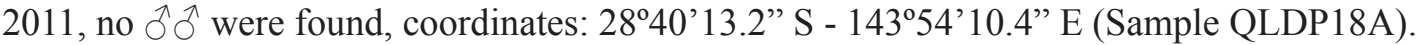
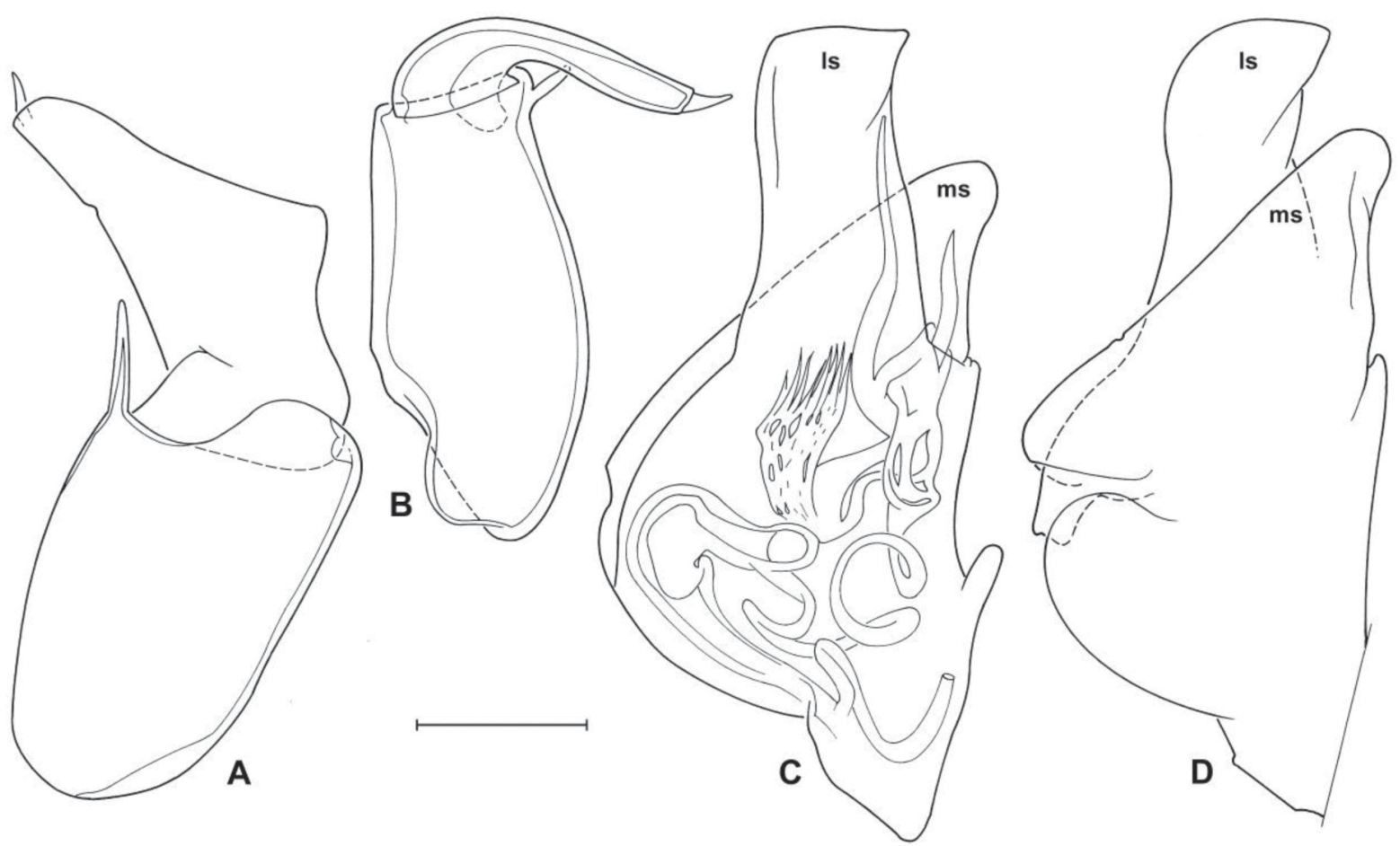

Fig. 5. Bennelongia dedeckkeri sp. nov. $(A=\mathrm{W} 40017 \& \mathrm{~B}-\mathrm{D}=\mathrm{W} 40016$ đ). A. Right prehensile palp. B. Left prehensile palp. C. Hemipenis showing inner anatomy. D. Outline of other hemipenis. Scales: $\mathrm{A}-\mathrm{B}=30.9 \mu \mathrm{m}, \mathrm{C}-\mathrm{D}=89.3 \mu \mathrm{m}$. 
These populations were the same Evolutionary Genetic species (Birky \& Barraclough 2009) as the type population, which confirmed morphological evidence that they belong to the same species as the type population.

\section{Differential diagnosis}

Bennelongia dedeckkeri sp. nov. belongs to the B. barangaroo lineage, because of its relatively small carapace size $(\mathrm{L} \approx 1000 \mu \mathrm{m})$, rounded dorsal margin, less pronounced anterior rostrum in dorsal view, less pronounced beak structure of the LV and reduced anteroventral overlapping of LV over RV. It can be distinguished from the other species in this lineage (B. barangaroo De Deckker, 1981 and B. mckenziei sp. nov.) by the pointed dorsal margin of the second Rpp segment (more rounded in B. barangaroo), the straight posterodorsal margin (hinge) of the RV (more rounded in B. barangaroo and B. mckenziei sp. nov.), the beak point of the carapace being positioned well above the ventral plane (positioned on the ventral plane in $B$. barangaroo) and the presence of an anteroventral and ventrally-pointed lapel on the RV (absent in B. mckenziei sp. nov.).

\section{Additional description}

Male and female Cp (Fig. 4E-H, K-L) similar in size and appearance with blunt anterior rostrum and blunt posterior side; in lateral view with rounded dorsal margin, LV overlapping RV on all sides, overlap narrow at middle of dorsal margin, greatest height slightly anterior of the middle; external valve surface hirsute with setae approximately $50 \mu \mathrm{m}$ in length.

Male and female LV (Fig. 4A, C) with rounded dorsal margin, greatest height situated slightly in front of the middle; anteroventral beak-like expansion small and blunt, point of beak well above ventral plane; ventral margin straight for approximately half its length; anterior inner list reaching well beyond the middle of the valve.

Male and female RV (Fig. 4B, D) with rounded dorsal margin anteriorly but straight posteriorly from the middle onwards (dorsal hinge); greatest height slightly anterior of the middle, outer list of RV with ventral row of tubercles; posterior list submarginal, but merging with selvage at beginning of straight dorsal margin (hinge); selvage at height of lapel expanded, lapel (Fig. 4I, J) broad, but running along short length of selvage with light serration sometimes visible.

Most appendages as typical of the genus and without special features.

First segment of Rpp (Fig. 5A) with rounded ventral margin and nearly straight dorsal margin, elongated, approximately $2 \mathrm{x}$ as long as central width, apically with one long slender sensory organ; second palp segment with margins diverging distally, distally pointed with sensory organ and also pointed on dorsal margin.

First segment of Lpp (Fig. 5B) with rounded ventral margin and nearly straight dorsal margin, narrowing distally; elongated, approximately $2 \times$ central width; sub-apically with sensory organ; second palp segment sickle shaped, approximately $0.75 \mathrm{x}$ as long as first segment and sharply curved asymmetrically over $180^{\circ}$, with distal sensory organ.

Hemipenes (Fig. 5C-D) with symmetrical outlines, ls protruding well beyond ms, tips of ls and ms well separated, ls distally pointed and ms with pointed ventral lobe.

\section{Ecology and distribution}

This species has been found in both permanent and ephemeral wetlands, occurring sympatrically with B. pinpi in Pelican Lake QLD and B. mckenziei sp. nov. in Cardenyabba Lagoon QLD (both species are 
similar in appearance). Males have been found in only some of these populations, suggesting that the others may be parthenogenetic, particularly in those localities in which other species of Bennelongia occur (B. pinpi in Pelican Lake and B. mckenziei in Cardenyabba Lagoon).

\section{Bennelongia mckenziei sp. nov. \\ urn:lsid:zoobank.org:act:321592CE-0627-4962-96CB-F1C7D26F6D8A}

Fig. 6

\section{Diagnosis}

Cp small $(\mathrm{L} \approx 1000 \mu \mathrm{m})$, in dorsal view with reduced anterior rostrum, blunt posterior and reduced anteroventral overlap of LV over RV; in lateral view with rounded dorsal margin, no visible anteroventral lapel and greatest height at the middle; LV with greatest height at the middle, anteroventral beak-like expansion not pointed, instead expressed as a linear horizontal extension of the LV ventral margin; RV with rounded margin near posterodorsal hinge, greatest height slightly anterior to the middle, anteroventral area without lapel, but with an expansion of the selvage.

Males unknown.

\section{Etymology}

This species is named after Dr K. McKenzie, who described the Bennelongia genus together with Dr P. De Deckker in 1981.

\section{Type material}

\section{Holotype}

q (W40071), with soft parts dissected in a sealed slide, RV and LV stored dry in a micropalaeontological slide.

\section{Paratypes}

q (W40068) with soft parts dissected in a sealed slide, two $q$ carapaces stored in separate micropalaeontological slides (W40072-W40073), क LV (W40069) and $\odot$ RV (W40070) stored dry in a micropalaeontological slide.

\section{Type locality}

Horseshoe Lagoon, Kilcowera Station, south of Thargomindah QLD, coordinates: 22²5'55.4" S $145^{\circ} 42^{\prime} 27.2^{\prime \prime}$ E. Material used for the present description was collected on 16 Jun. 2011 by AK (Sample QLDP21C).

Measurements (in $\mu \mathrm{m}$ )

O): RV: $\mathrm{L}=1082, \mathrm{H}=660 . \mathrm{LV}: \mathrm{L}=1078, \mathrm{H}=626 . \mathrm{Cp}: \mathrm{L}=1008-1060(n=2), \mathrm{W}=618-647(n=2)$, $\mathrm{H}=622$.

\section{Other material investigated}

Cardenyabba Lagoon, Kilcowera Station, south of Thargomindah QLD, collected by AK on 14 Jun. 2011, coordinates: $28^{\circ} 41^{\prime 2} 23.2^{\prime \prime} \mathrm{S}-143^{\circ} 56^{\prime} 35^{\prime \prime}$ E. This population was the same Evolutionary Genetic species (Birky \& Barraclough 2009) as the type population, which confirmed morphological evidence that they belong to the same species as the type population. 


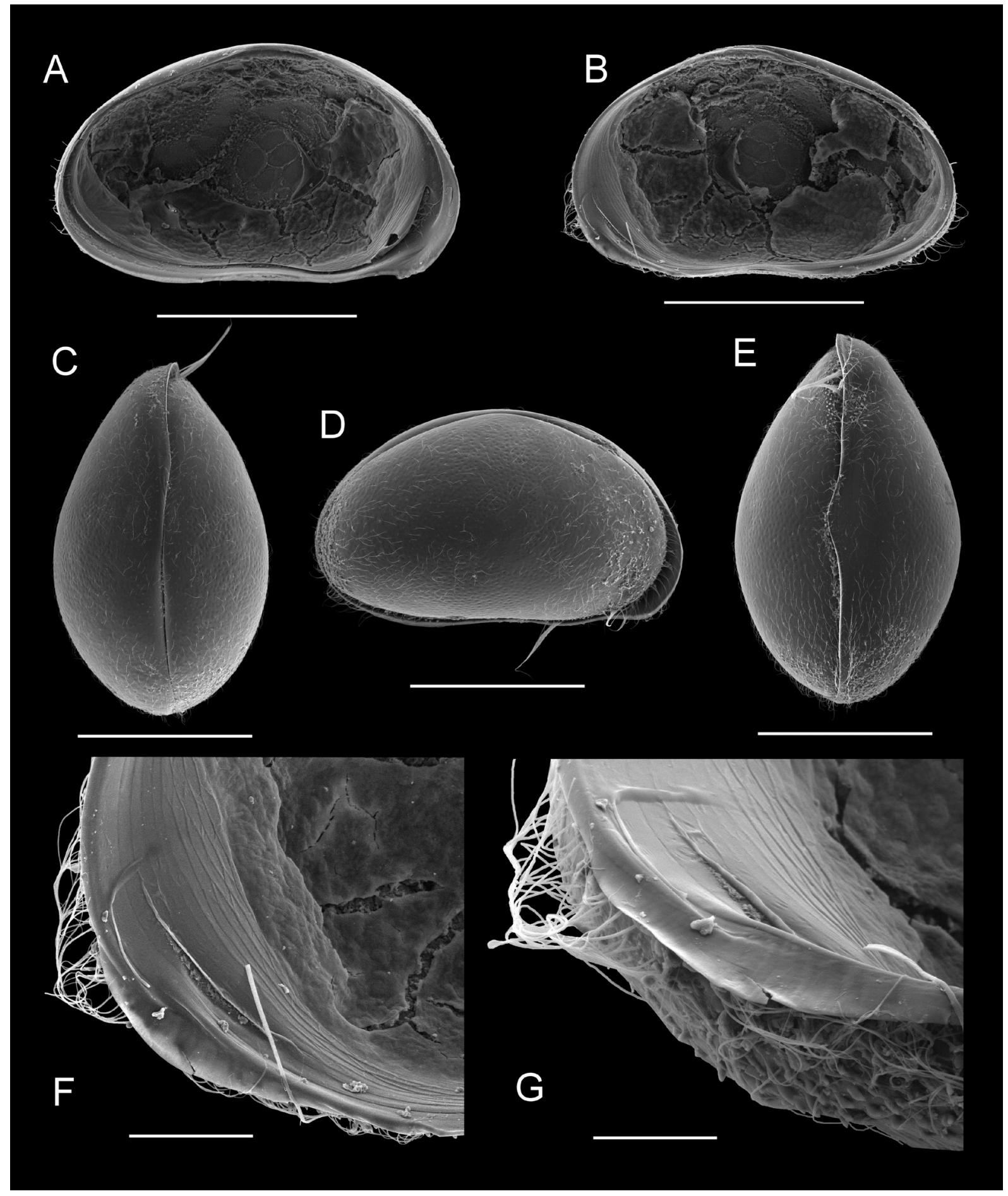

Fig. 6. Bennelongia mckenziei sp. nov., all from Horseshoe Lagoon, QLD (Type locality). A. Holotype

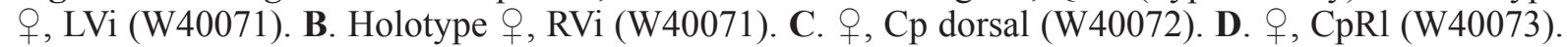
E. Holotype ${ }_{+}, \mathrm{Cp}$ ventral (W40071). F. Holotype + , RVi detail anteriorly (W40071). G. Holotype + , RVi detail anteriorly (W40071). Scales: A-E $=500 \mu \mathrm{m}, \mathrm{F}-\mathrm{G}=100 \mu \mathrm{m}$. 


\section{Differential diagnosis}

Bennelongia mckenziei sp.nov. belongs to the B. barangaroo lineage, because of its relatively small carapace size $(\mathrm{L} \approx 1000 \mu \mathrm{m})$, rounded dorsal margin, less pronounced anterior rostrum in dorsal view, less pronounced beak structure of the LV and reduced anteroventral overlapping of LV over RV. It can be distinguished from the other species in this lineage (B. dedeckkeri sp. nov. and B. barangaroo De Deckker, 1981) by the fact that the greatest height of the Cp is at the middle (slightly anterior in $B$. dedeckkeri sp. nov.), the rounded posterodorsal margin of the RV hinge (straight in B. dedeckkeri sp. nov.), the absent anteroventral lapel of the RV (present in B. barangaroo and B. dedeckkeri sp. nov.), the rounded anteroventral margin of the LV (pointed in B. dedeckkeri sp. nov. and B. barangaroo), and the straight ventral margin of the LV extending to the distal point of the beak (sinuous ventral margin and more pronounced anteroventral beak structure in B. dedeckkeri sp. nov. and B. barangaroo). As no males are known for this species, we cannot compare shapes of prehensile palps and of hemipenes.

\section{Additional description of female}

$\mathrm{Cp}$ in dorsal and ventral view egg shaped (Fig. 6C, E), with blunt anterior and posterior ends; in lateral view (Fig. 6D) with rounded dorsal margin, greatest height in the middle, LV overlapping RV on all sides, overlap narrow at middle of dorsal margin; external valve surface hirsute with setae approximately $50 \mu \mathrm{m}$ in length.

LV (Fig. 6A) with rounded dorsal margin, greatest height at the middle, anteroventral beak-like expansion not pointed, instead expressed as a linear horizontal extension of the LV ventral margin; ventral margin straight over $c$. two thirds of its length.

RV (Fig. 6B, F-G) with rounded dorsal margin, rounded margin near posterodorsal hinge, greatest height situated slightly anterior of the middle; outer list with ventral row of tubercles; posterior inner list submarginal, but merging with selvage at beginning of dorsal hinge; anteroventral area without lapel or bulbous expansion of the valve margin, instead only an expansion of the selvage in this area visible.

Female appendages as typical of the genus and without special features.

Male unknown.

\section{Ecology and distribution}

The species has been recorded in a limited distribution, namely two localities on Kilcowera Station, south of Thargomindah QLD. No males were found in either of the two recorded localities, which suggested the populations were parthenogenetic, particularly in Cardenyabba Lagoon where it was recorded sympatrically with $B$. dedeckkeri sp. nov.

\section{Bennelongia nimala lineage}

\section{Remarks}

The B. nimala lineage consists of two nominal species, B. nimala De Deckker, 1981 and the here described $B$. regina sp. nov. The lineage is characterized by oval carapaces in dorsal view with hirsute and pustulose shell surfaces and a pronounced overlap of the RV by the LV anteroventrally, more so than in other species of Bennelongia.

Species in this lineage can be distinguished from all other lineages of Bennelongia by their heavily hirsute and pustulose shell surfaces. They can also be distinguished from the $B$. cygnus lineage by the serrated margin of the anteroventral lapel on the RV, from the $B$. tunta lineage by the rounded dorsal margin in lateral view (rectangular in $B$. tunta), from the $B$. pinpi lineage it differs by the presence of an 
anteroventral lapel in the RV (absent in B. pinpi lineage), from the B. australis lineage by the smaller male adult carapace size $(\mathrm{L} \approx 1400 \mu \mathrm{m})$ and serrated margin of the RV anteroventral lapel (smooth in $B$. australis lineage), and from the $B$. harpago lineage by the absence of a dorsal hump-like thickening of the LV (present in B. harpago).

Bennelongia regina sp. nov.

urn:1sid:zoobank.org:act:EC592D84-3E90-4F5A-BB64-9C0CCF5DA2CA

Figs 7-8

\section{Diagnosis}

$\mathrm{Cp}$ with well-developed anterior rostrum in dorsal view, LV heavily overlapping RV anteroventrally, posteriorly blunt; in lateral view with rounded dorsal margin, LV overlapping RV on all sides. LV with broadly rounded anteroventral beak and rounded dorsal margin. $\mathrm{RV}$ with rounded dorsal margin, greatest height situated slightly anterior of the middle, anteroventral lapel broad, serrated and with its distal margin running parallel to selvage. Hemipenes with ls protruding well beyond ms, tips of ls and ms separated; ls distally pointed and ms dorsally with in-fold. Rpp with first segment with rounded ventral margin, long subapical sensory organ and broad second segment. Lpp with proximal segment elongated with nearly parallel margins over two thirds of the segment length, distal segment sickle shaped, much shorter than proximal segment.

\section{Etymology}

The Latin "Regina" means Queen; the species has been named as such due to its location within Queensland, but also for its splendour in appearance.

\section{Type material}

\section{Holotype}

$\widehat{\partial}$ (W40060), with soft parts dissected in a sealed slide and valves stored dry in a micropalaeontological slide.

\footnotetext{
Allotype

q (W40074), with carapace stored dry in a micropalaeontological slide.
}

\section{Paratypes}

Three $\delta$ carapaces stored in a micropalaeontological slide (W40062-W40064), three $q$ carapaces stored in a micropalaeontological slide (W40065-W40067), $q$ RV and LV (W40061) stored in a micropalaeontological slide.

Several in toto specimens in EtOH (W40077).

\section{Type locality}

Horseshoe Lagoon, Kilcowera Station, south of Thargomindah QLD; coordinates: 28 39'57" S $143^{\circ} 53^{\prime} 42.4^{\prime \prime}$ E. Material used for the present description was collected on 16 Jun. 2011 by AK (Sample QLD21A).

$$
\begin{aligned}
& \text { Measurements (in } \mu \mathrm{m}) \\
& \text { o: } \mathrm{RV}: \mathrm{L}=1381, \mathrm{H}=825 . \mathrm{LV}: \mathrm{L}=1467, \mathrm{H}=889 . \mathrm{Cp}: \mathrm{L}=1431-1471(n=2), \mathrm{W}=852-906 . \\
& \text { o: } \mathrm{RV}: \mathrm{L}=1667, \mathrm{H}=1012 . \mathrm{LV}: \mathrm{L}=1769, \mathrm{H}=1079 . \mathrm{Cp}: \mathrm{L}=1687-1817(n=2), \mathrm{W}=1002-1102(n=2) \text {, } \\
& \mathrm{H}=1079 .
\end{aligned}
$$




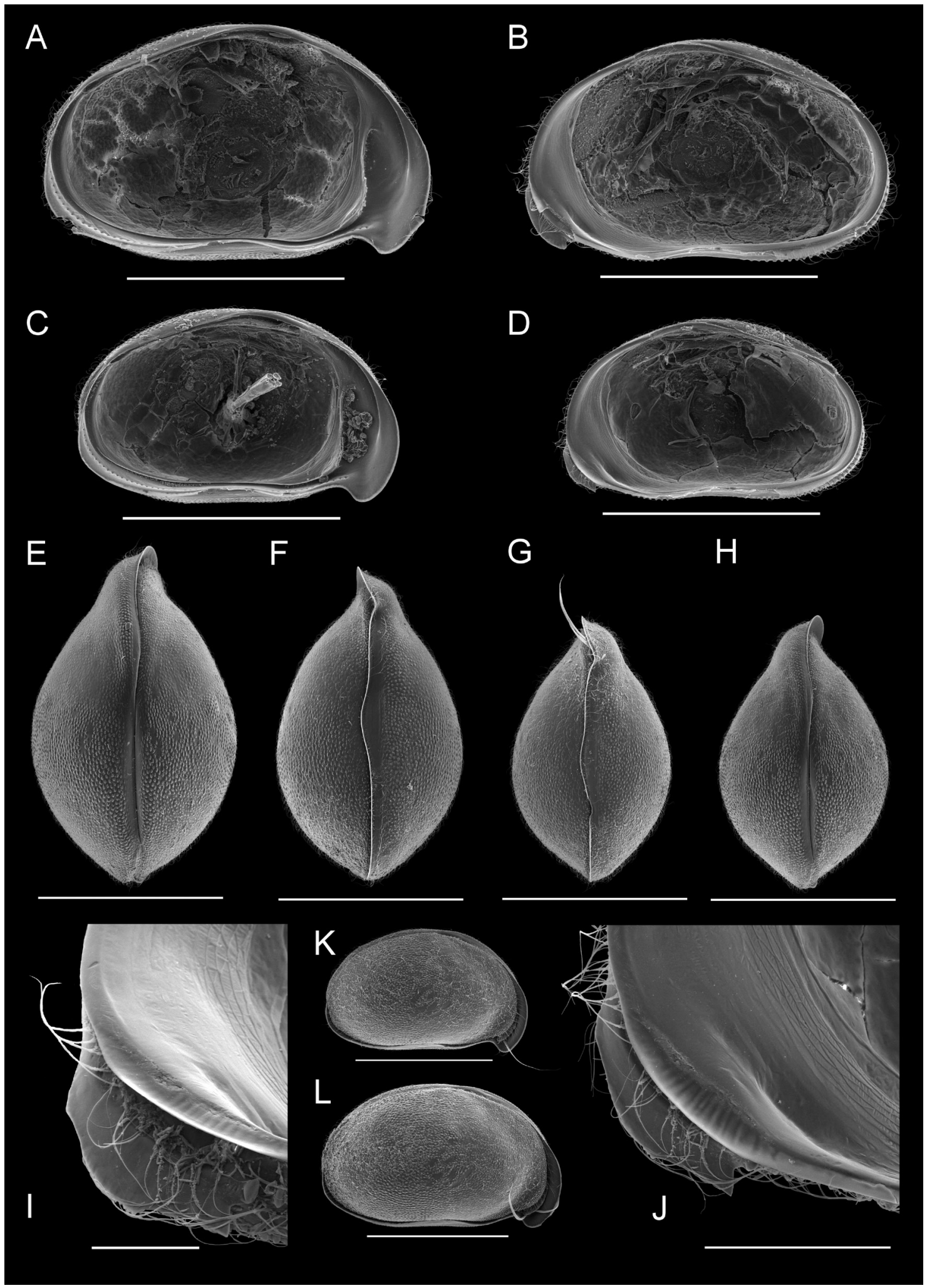

Fig. 7. Bennelongia regina sp. nov., all from Horseshoe Lagoon, QLD (Type locality). A. + , LVi

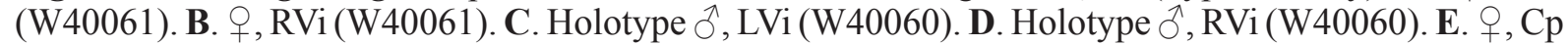

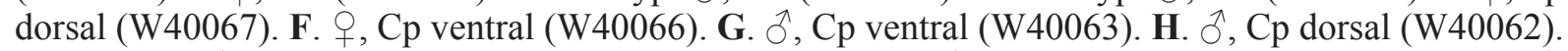
I. Holotype $\widehat{\partial}$, RVi detail anteriorly (W40060). J. Holotype $\widehat{\partial}$, RVi detail anteriorly (W40060). K. $\partial^{\lambda}$, CpRl (W40064). L. Allotype + , CpRl (W40074). Scales: A-H, K-L $=1000 \mu \mathrm{m}, \mathrm{J}=200 \mu \mathrm{m}, \mathrm{I}=100 \mu \mathrm{m}$. 


\section{Other material investigated}

The species is thus far known only from its type locality.

\section{Differential diagnosis}

Bennelongia regina sp. nov. belongs to the $B$. nimala lineage because of its hirsute and pustulose valve surface and the large anteroventral overlap of the RV by the LV. It can be distinguished from the other species in this lineage (B. nimala De Deckker, 1981) by the reduced anterodorsal hump-like thickening of the LV in lateral view, the shorter and less abundant setae on the valve surface, the slender ls and the absence of a circular lump shaped copulatory sheath of the hemipenis, the rounded ventral margin of the first Rpp segment, the long subapical sensory organ on the first Rpp segment and the parallel margins of the first Lpp segment.

\section{Additional description}

Male and female carapaces in dorsal and ventral view oval shaped with rostrum well-developed, and with large anteroventral overlap of the RV by the LV (Fig. 7E-H, K-L); greatest width situated slightly posterior to the middle (Fig. 7E-H). Carapace in lateral view with rounded dorsal margin and LV overlapping RV on all sides (Fig. 7K-L); greatest height situated near the middle; anterior rostrum (in dorsal view) well-developed, posteriorly bluntly pointed. External valve surface pustulose and hirsute, with setae approximately $50 \mu \mathrm{m}$ in length. Male valves smaller than female valves, but otherwise similar in appearance.

Male and female LV (Fig. 7A, C) with rounded dorsal margin, greatest height situated slightly in front of the middle; anteroventral beak-like expansion large and broadly rounded; ventral margin almost straight over approximately half its length; anterior inner list reaching well beyond the middle of the valve.

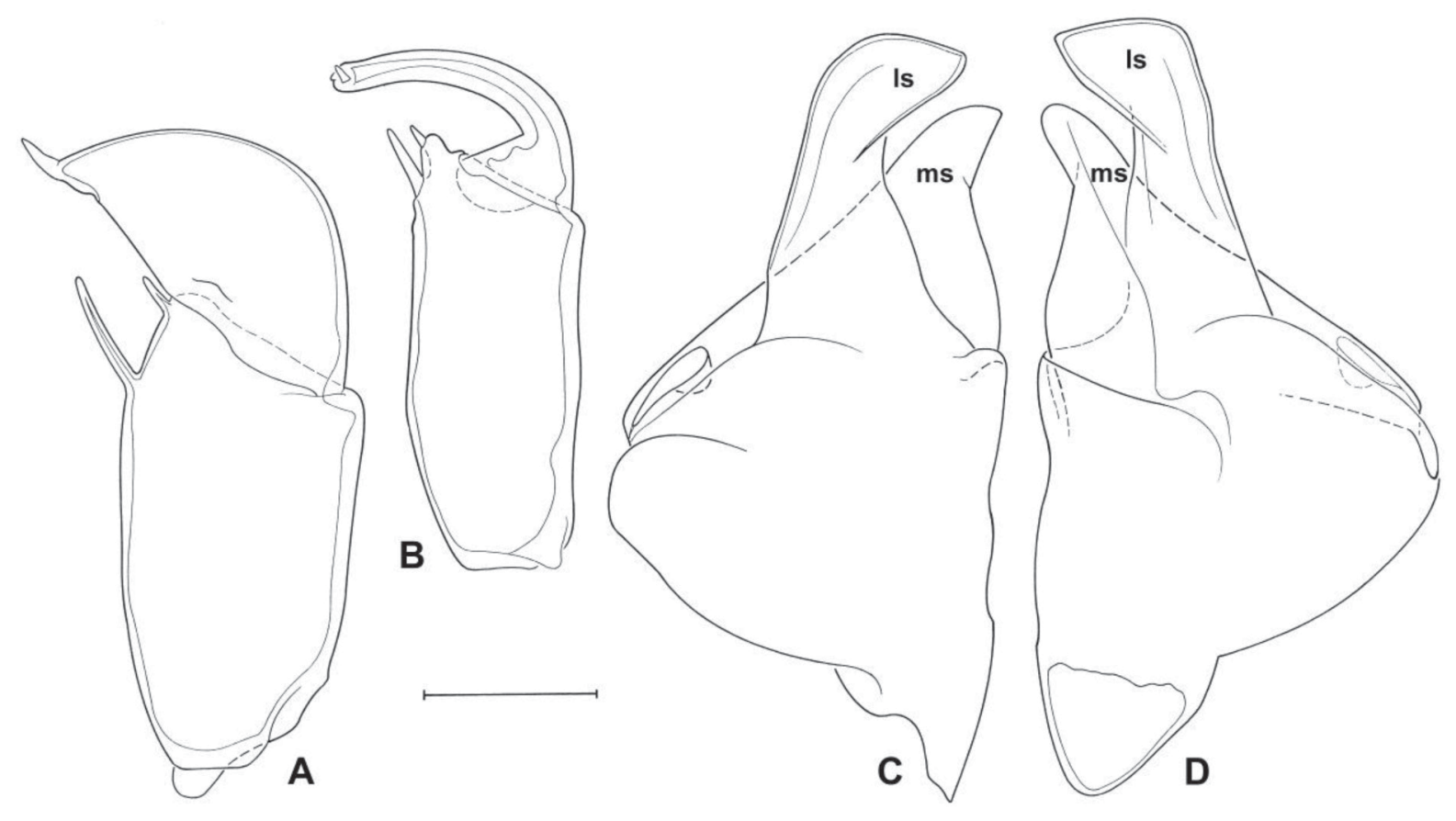

Fig. 8. Bennelongia regina sp. nov. (all from holotype $\widehat{\partial}=$ W40060). A. Right prehensile palp. B. Left prehensile palp. C. Hemipenis. D. Outline of other hemipenis. Scales: A-B $=89.3 \mu \mathrm{m}, \mathrm{C}-\mathrm{D}=104.2 \mu \mathrm{m}$. 
Male and female RV (Fig. 7B, D) with rounded dorsal margin, greatest height situated slightly anterior of the middle; outer list of right valves with ventral row of tubercles (Fig. 7B, D); posterior selvage submarginal, posterior list merging with selvage at dorsal hinge; selvage at height of lapel expanded, striate; lapel (Fig. 7I-J) broad, serrated and with distal margin running parallel to selvage.

Most appendages as typical of the genus and without special features.

First segment of Rpp (Fig. 8A) with rounded ventral margin and straight dorsal margin, elongated, approximately $2 \mathrm{x}$ as long as central width, subapically with one long slender sensory organ, apically with shorter sensory organ, both situated quite far apart; second palp segment sub-triangular, broad and with rounded distal margin; apically with slender sensory organ.

First segment of Lpp (Fig. 8B) with parallel margins over two thirds of the length, but narrowing in proximal third, elongated, more than $2.7 \mathrm{x}$ as long as central width, subapically with one long slender sensory organ, apically with shorter sensory organ on elongated outgrowth; second palp segment sickleshaped, approximately $0.75 \mathrm{x}$ as long as first segment and asymmetrically curved over $c .180^{\circ}$, with small distal sensory organ.

Hemipenes (Fig. 8C-D) outlines asymmetrical, one hemipenis with ms having two lobes that embrace the ls on inner and outer sides (Fig. 8D), one lobe distal and embracing the ls as a three dimensional structure and the other lobe proximal and incomplete. The other hemipenis (Fig. 8C) with ms having a single lobe only embracing the ls on the outer side. Both hemipenes with ls protruding well beyond $\mathrm{ms}$, tips of 1s and ms well-separated, ls distally pointed ventrally; $\mathrm{ms}$ with pointed ventral lobe, dorsally with in-folding of $\mathrm{ms}$.

\section{Ecology and distribution}

The species has thus far been found only in its type locality, a turbid temporary freshwater pool with small macrophytes. The species co-existed with another Bennelongia species (B. mckenziei sp. nov. - assumed to be parthenogenetic) and several macroinvertebrates. No further environmental data are available.

\section{Bennelongia pinpi lineage}

\section{Remarks}

The combination of a pronounced anteroventral beak-like structure of the LV with the absence of an anteroventral lapel of the RV and bulbous expansion in its place will enable the diagnosis of this lineage amongst all currently described Bennelongia species as detailed in Martens et al. (2012).

Bennelongia pinpi De Deckker, 1981

Figs 9-10

\section{Remarks}

Bennelongia pinpi De Deckker, 1981 was described from Pine Tree Creek Lagoon, north of Hughenden in Queensland, Australia. The species was characterized by its strongly pronounced beak-like expansion of the LV and the outline of the hemipenes (De Deckker 1981). At the time of the description these characters were unique and enabled a simple diagnosis of the species. Since then, two more species from within the same lineage have been described (Martens et al. 2012) that are closely related to B. pinpi with respect to the absence of anteroventral lapel on the RV, the formation of a bulbous expansion in that place, and the hemipenis outline. Furthermore, some characters were found to be variable within $B$. pinpi upon examination of non-type populations, making the diagnosis of $B$. pinpi from its lineage sister taxa less obvious than is indicated in its description. Illustrations showing the variability within this 


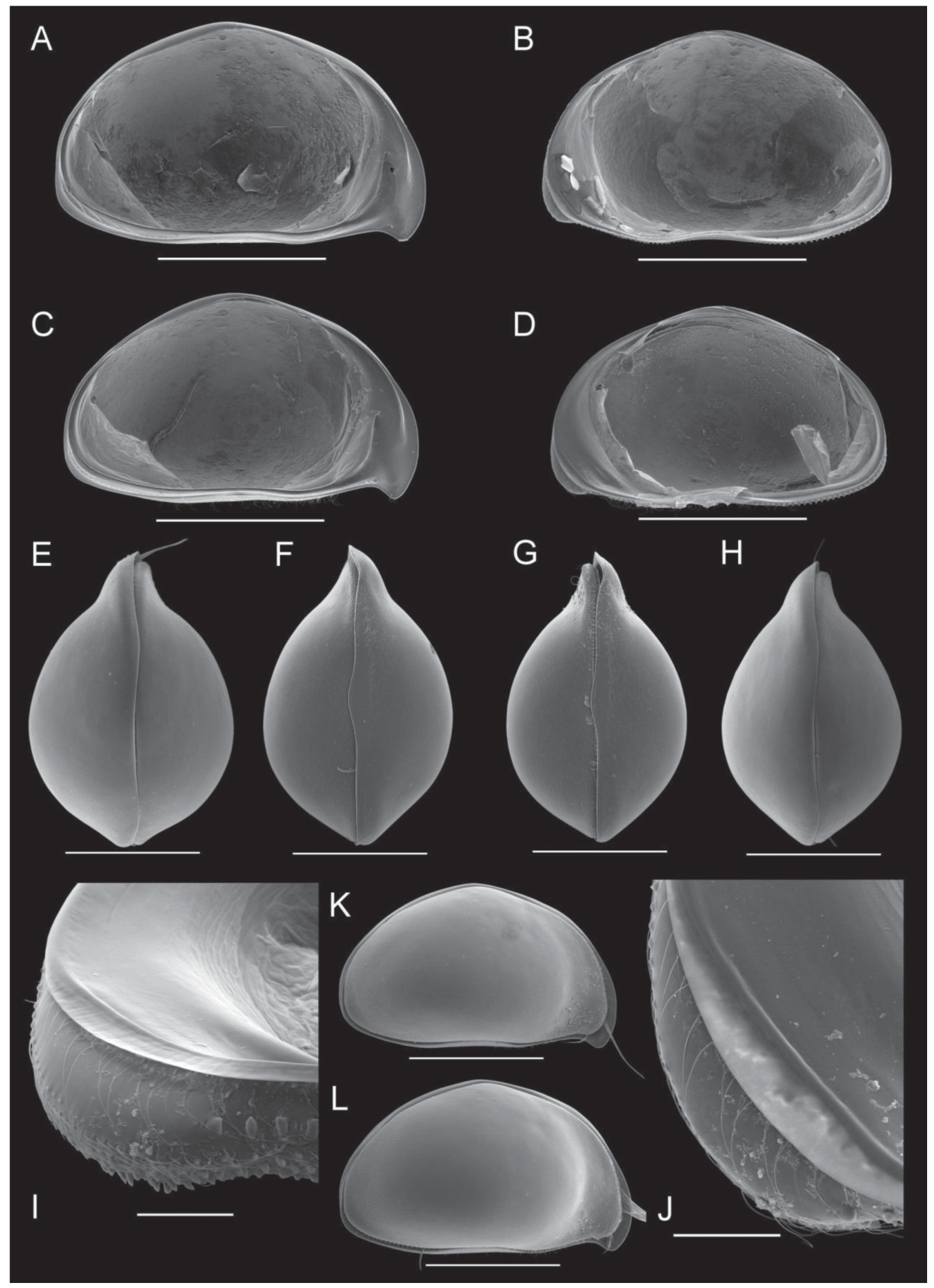

Fig. 9. Bennelongia pinpi De Deckker, 1981, all from Salt Lake, north of Hughenden, QLD. A. +

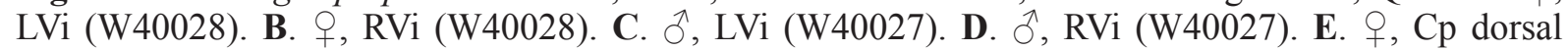

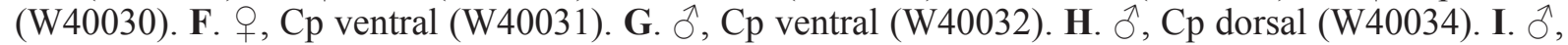

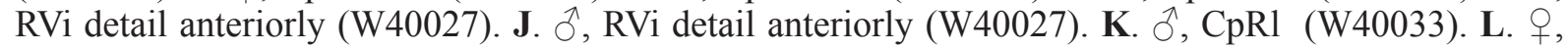
CpRl (W40029). Scales: A-H, K-L $=1000 \mu \mathrm{m}, \mathrm{J}-\mathrm{I}=100 \mu \mathrm{m}$. 


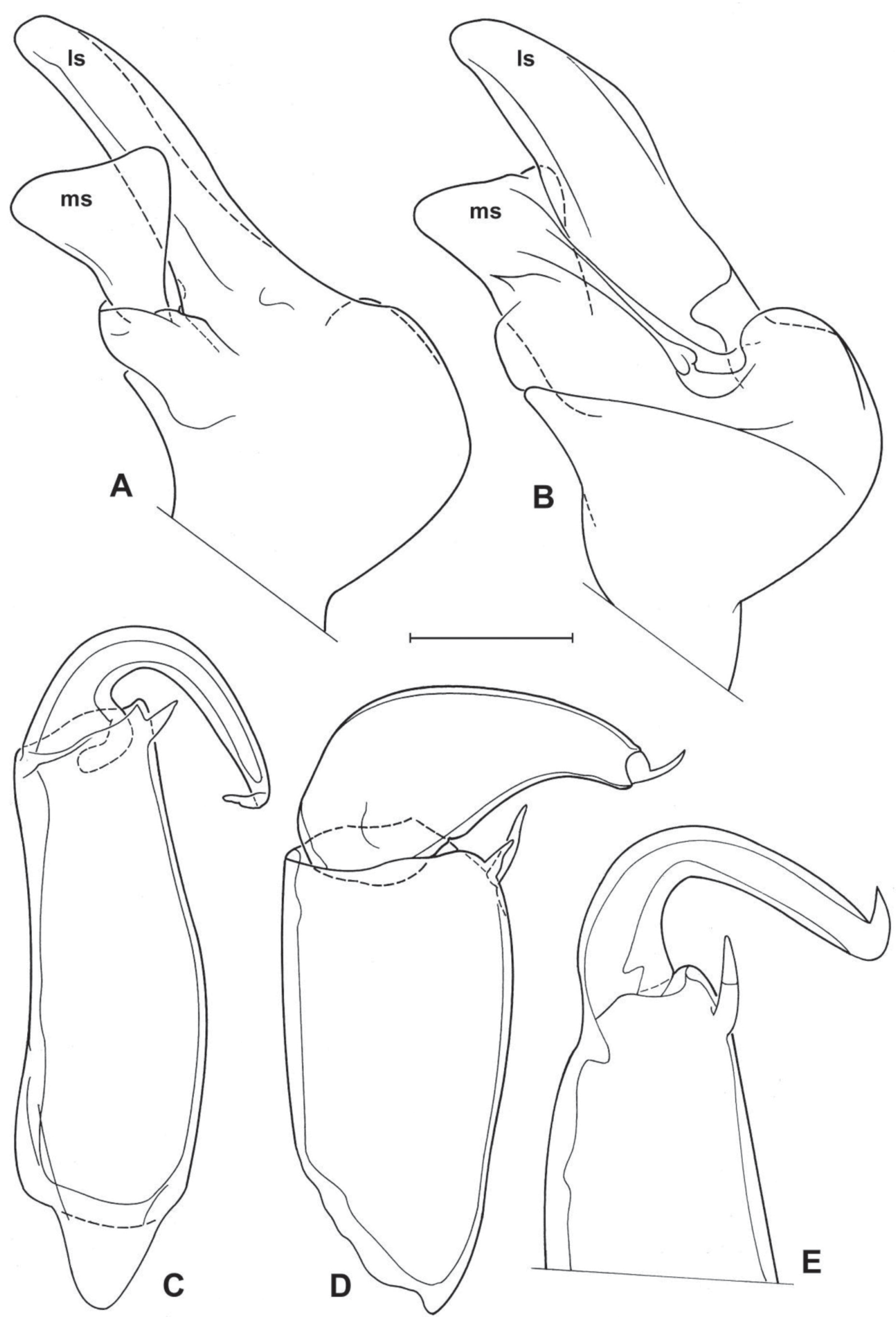

Fig. 10. Bennelongia pinpi De Deckker, 1981. $(\mathrm{A}-\mathrm{D}=\mathrm{W} 40043$ from Pelican Lake QLD, $\mathrm{E}=\mathrm{W} 40035$ from Lake Louisa QLD). A-B. Outlines of hemipenes. C. Left prehensile palp. D. Right prehensile palp. E. Left prehensile palp. Scales: A-B $=156.3 \mu \mathrm{m}, \mathrm{C}-\mathrm{D}=89.3 \mu \mathrm{m}, \mathrm{E}=42.6 \mu \mathrm{m}$. 
species were needed to help elucidate the diagnostic characters that can be used for their identification. Thus, detailed drawings of the hemipenes and prehensile palps from non-type localities are provided, which alongside the $B$. pinpi description (De Deckker 1981) show the expected variability within the species and the characters that allow their diagnosis from the more recently described $B$. strellyensis Martens et al., 2012 and B. kimberleyensis Martens et al., 2012.

\section{Diagnosis (modified after De Deckker 1981)}

$\mathrm{Cp}$ with pronounced anterior rostrum but bluntly pointed posterior; sub-triangular in right lateral view, circular in dorsal/ventral view (more so in females), LV overlapping RV on all sides, external valve surface smooth to pseudopunctate with sparsely distributed setae restricted to ventral and anteroventral region. LV with pronounced anteroventral beak-like expansion often extending below plane of horizontal ventral margin. RV with anteroventral flange or lapel absent, but with bulbous expansion of outer list in its place; anterior selvage with flange-like expansion and additional inner submarginal list. Rpp with proximal segment approximately two times as long as central width, distal palp segment short and triangular with rounded distal margin and apical sensory organ. Lpp with first segment over three times as long as central width; second palp segment sickle-shaped, short, and variably rounded, sometimes by over 180 degrees. Hemipenis with ls protruding well beyond ms, more so than any other described species in this lineage; ms forming a three dimensional structure, embracing ls on three sides, dorsal lobe with rounded distal margin.

\section{Measurements (in $\mu \mathrm{m}$ )}

đ: RV: $\mathrm{L}=1998-2095(n=3), \mathrm{H}=1175-1218(n=3) . \mathrm{LV}: \mathrm{L}=2208-2223(n=3), \mathrm{H}=1293-1320(n=3)$.

Cp: $\mathrm{L}=2063-2232(n=9), \mathrm{W}=1285-1523(n=3), \mathrm{H}=1258-1368(n=3)$.

ㅇ: $\mathrm{RV}: \mathrm{L}=2080-2103(n=3), \mathrm{H}=1233-1273(n=2) . \mathrm{LV}: \mathrm{L}=2200-2280(n=2), \mathrm{H}=1288-1335(n=2)$. $\mathrm{Cp}: \mathrm{L}=2055-2300(n=7), \mathrm{W}=1195-1265(n=5), \mathrm{H}=1218-1300(n=2)$.

\section{Localities investigated}

Salt Lake, freshwater lake north of Hughenden on Kennedy Developmental Highway QLD, collected on 9 Jun. 2011 by RS and AK, coordinates: 1951'19.9" S - 144'16'11.3" E (Sample QLDP11A).

Pelican Lake, north of Hughenden on Kennedy Developmental Highway QLD, collected on 9 Jun. 2011 by RS and AK, coordinates: 19²51'53.1” S - 144'15'20" E (Sample QLDP13A).

Lake Louisa, north of Hughenden on Kennedy Developmental Highway QLD, collected on 9 Jun. 2011 by RS and AK, coordinates: 1953'45.6” S - 144¹5’55.5” E (Sample QLDP12A).

\section{Material investigated or illustrated}

ðð from Pelican Lake (W40043), Salt Lake (W40027) and Lake Louisa (W40035), with soft parts dissected in sealed slide, valves stored dry in a micropalaeontological slide. Three $\delta$ carapaces from Pelican Lake (W40045-W40047), Salt Lake (W40029-W40031) and Lake Louisa (W40037-W40039) stored in a micropalaeontological slide.

우우 from Pelican Lake (W40044), Salt Lake (W40028) and Lake Louisa (W40036) with soft parts dissected in sealed slide, valves stored dry in a micropalaeontological slide. Three $q$ carapaces from Pelican Lake (W40048-W40050), Salt Lake (W40032-W40034) and Lake Louisa (W40040-W40042) stored in a micropalaeontological slide.

Several in toto specimens in EtOH from Pelican Lake (W40080). 


\section{Differential diagnosis}

Bennelongia pinpi can be diagnosed as within the B. pinpi lineage due to its large carapace, well developed anterior rostrum, blunt posterior, the bulbous expansion of the valve in place of the absent anteroventral lapel of the RV, the well-developed anteroventral beak-like expansion of the LV and the well sclerotized hemipenes with a three dimensional ms enveloping the ls.

It can be distinguished from the other species in this lineage by the elongated first Lpp segment (shorter in B. strellyensis Martens et al., 2012 and B. kimberleyensis Martens et al., 2012), the rounded dorsal margin of the Rpp second segment (triangular-pointed in B. kimberleyensis Martens et al., 2012), the narrow ls of the hemipenis (broader in B. strellyensis Martens et al., 2012 and B. kimberleyensis Martens et al., 2012) and the extension of the ls far beyond the ms (much less extended in B. strellyensis Martens et al., 2012 and B. kimberleyensis Martens et al., 2012).

\section{Additional description (modified after De Deckker 1981)}

Cp (Fig. 9E-H) with pronounced anterior rostrum but bluntly pointed posterior; sub-triangular in right lateral view (Fig. 9K-L), circular in dorsal/ventral view (more so in females), LV overlapping RV on all sides, external valve surface smooth to pseudopunctate with sparsely distributed setae restricted to ventral and anteroventral region.

LV (Fig. 9A, C) with pronounced anteroventral beak-like expansion, often extending below plane of horizontal ventral margin, dorsal margin highest at valve mid-point.

RV (Fig. 9B, D) in lateral view with dorsal margin highest at valve mid-point; anteroventral flange or lapel absent, but with bulbous expansion of outer list in its place (Fig. 9I-J); anterior selvage with flangelike expansion, and additional inner submarginal list.

Most appendages as typical of the genus and without special features.

Rpp (Fig. 10D) with first segment approximately two times as long as central width, subapically with two slender sensory organs, one long and one short often overlapping; second palp segment short and triangular with rounded distal margin and apical sensory organ.

Lpp (Fig. 10C, D) with first segment over three times as long as central width, subapically with one sensory organ; apically with rounded outgrowth; second palp segment sickle-shaped, short, and variably rounded (Fig. 10C versus Fig. 10E), sometimes by over 180 degrees with distal sensory organ.

Hemipenes (Fig. 10A-B) with width of ls variable depending on slide preparation (Fig. 10a vs Fig. 10B), 1s protruding well beyond ms, more so than any other described species in this lineage; ms consisting of three lobes, distal part of ms produced into a three-dimensional lobe embracing the ls on proximal and distal sides, a small additional dorsal lobe with rounded distal margin, and a proximal lobe nearly straight and incomplete.

\section{Ecology and distribution}

The distribution of B. pinpi appears to be isolated to an area north of Hughenden. At the time of its description, the species had been found in Pine Tree Creek Lagoon, Agnes Lake, Salt Lake and Louisa Lake (De Deckker 1981). It appears that most of these populations still exist. Here, an additional locality (Pelican Lake) is recorded. 


\section{Bennelongia harpago lineage}

\section{Remarks}

This lineage only consists of one species (B. harpago De Deckker, 1981), which can be diagnosed from the other described lineages of Bennelongia by using the description below.

\section{Bennelongia harpago De Deckker, 1981}

Fig. 11

Diagnosis (modified after De Deckker 1981)

$\mathrm{Cp}$ in dorsal view with blunt anterior rostrum and rounded posterior, oval to sub-rectangular in lateral view, LV overlapping RV on all sides but more so antero-dorsally with hump-like thickening. External valve surface pseudopunctate with sparse, short setae. LV with dorsal margin highest at one third from the anterior where hump-like thickening occurs. RV with anteroventral flange absent and greatest height slightly anterior of the middle.

\section{Measurements (in $\mu \mathrm{m}$ )}

of: $\mathrm{RV}: \mathrm{L}=1193, \mathrm{H}=736 . \mathrm{LV}: \mathrm{L}=1261, \mathrm{H}=792 . \mathrm{Cp}: \mathrm{L}=1256-1282(n=3), \mathrm{W}=813, \mathrm{H}=765-788$ $(n=2)$.

\section{Locality investigated}

Lake Powlathanga, west of Charters Towers QLD, coordinates: 20¹4'42.2" S - 145'58'8.2" E. Material was collected on 5 Jun. 2011 by RS and AK (Sample QLDP1A).

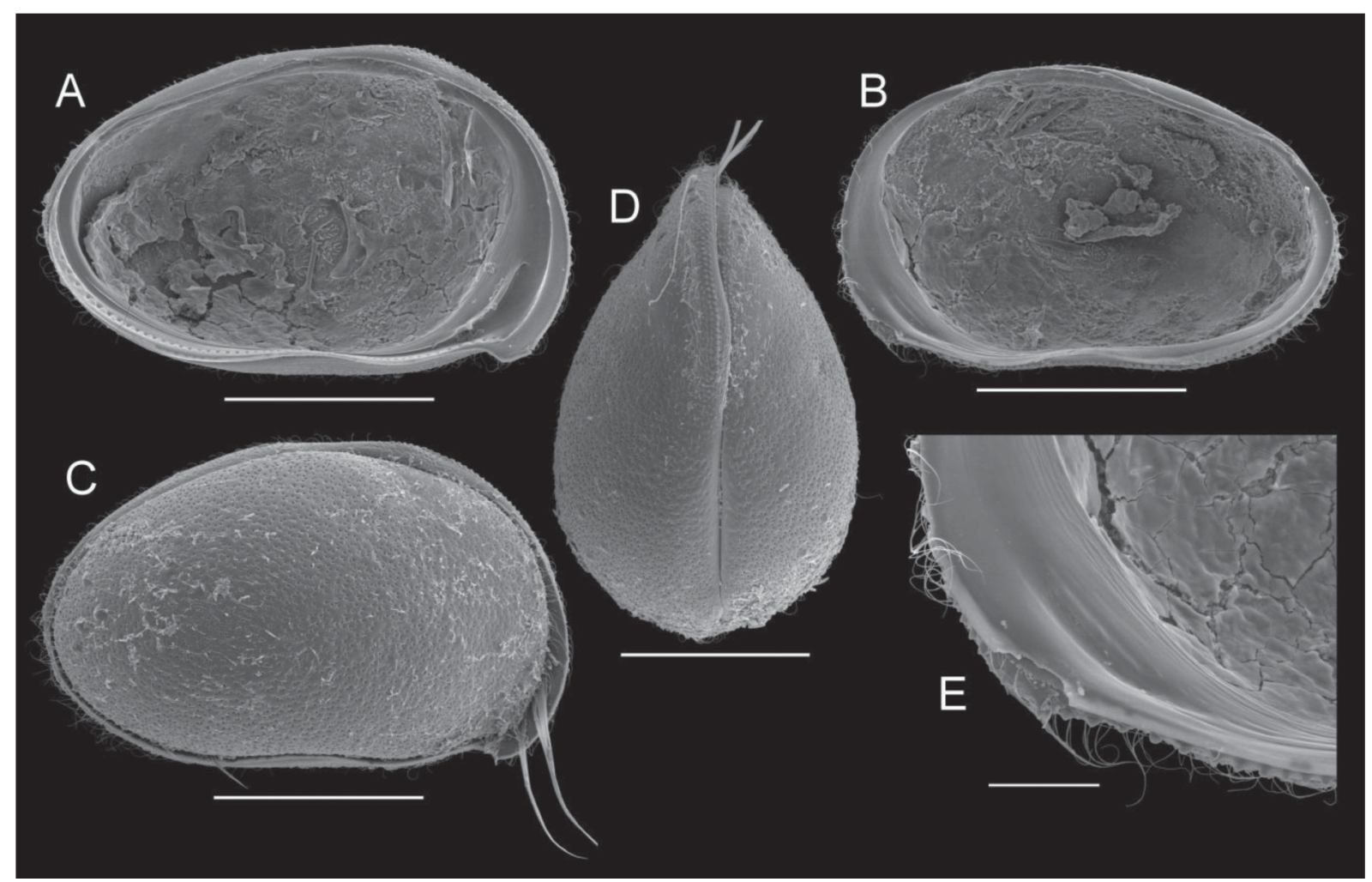

Fig. 11. Bennelongia harpago De Deckker \& Mckenzie, 1981, all from Lake Powlathanga, QLD. A. + LVi (W40014). B. ㅇ, RVi (W40014). C. ㅇ, CpRl (W40015). D. ㅇ, Cp dorsal (RS35). E. ㅇ, RVi detail anteriorly (W40014). Scales: A-D $=500 \mu \mathrm{m}, \mathrm{E}=100 \mu \mathrm{m}$. 


\section{Material investigated}

Two 우우 (W40013-W40014) from Lake Powlathanga, with soft parts dissected in a sealed slide and valves stored dry in a micropalaeontological slide. One carapace stored in a micropalaeontological slide (W40015).

\section{Differential Diagnosis}

Bennelongia harpago can be diagnosed from the other Bennelongia lineages by the anterodorsal hump-like thickening of the LV (absent in all other described lineages). Identification can be confirmed further by the small carapace ( $\mathrm{L} \approx 1.2 \mathrm{~mm}$, larger in B. cygnus, $B$. australis, B. pinpi, B. tunta and B. nimala lineages), the absence of an anteroventral lapel in the RV (present in B. cygnus, B. australis and B. nimala lineages) and the blunt anterior rostrum in dorsal view (more pronounced in B. australis, B. pinpi and B. tunta lineages).

\section{Additional Description (modified after De Deckker \& McKenzie 1981)}

Cp (Fig. 11C-D) oval in dorsal view with rounded posterior and blunt anterior rostrum; oval to subrectangular in lateral view, LV overlapping RV on all sides (more so in the first one third from anterior, external valve surface pseudopunctate with sparse short setae.

LV (Fig. 11A) with pointed anteroventral beak-like expansion, dorsal margin highest at approximately one third from anterior where thickening of the valve forms a hump-like appearance.

RV (Fig. 11C) in lateral view with dorsal margin highest at slightly anterior to the middle. Anteroventral lapel very reduced to non-existent.

\section{Remarks}

Bennelongia harpago was described from a dam near Mt Teddy in Queensland, Australia (De Deckker $\&$ McKenzie 1981). This study has provided molecular evidence from specimens in Lake Powlathanga that confirmed their species status. As there have since been nine additional species described from Western Australia and three described here, notes on the additional characters that now diagnose B. harpago from all described Bennelongia are provided below.

\section{Ecology and distribution}

Bennelongia harpago was originally recorded at a number of localities throughout Queensland (De Deckker \& McKenzie 1981). One of these populations (Lake Powlathanga) was sampled in this study showing that they still exist there. At present, males have not been recorded for this species.

\section{Bennelongia australis lineage}

\section{Remarks}

The diagnostic characters provided for this lineage in Martens et al. (2012) are still valid after the revision of eastern Australian Bennelongia species. The combination of a large carapace, intermediate anteroventral beak-like structure of the LV, presence of an anteroventral lapel on the RV, rounded dorsal margin and pronounced anterior rostrum in dorsal view will still enable the diagnosis of this lineage amongst all described Bennelongia species. 


\section{Bennelongia cuensis sensu lato}

Figs 12-13

\section{Diagnosis}

Cp large $(\mathrm{L} \approx 1800 \mu \mathrm{m})$ with strong anterior rostrum and bluntly pointed posterior in dorsal view. $\mathrm{LV}$ strongly overlapping RV on all sides, LV with straight dorsal margin and bluntly pointed anteroventral beak. RV with broad and elongated anteroventral lapel running parallel to the selvage. Hemipenis with distal margin of ms straight and broad, producing a pointed ventral and a rounded dorsal lobe; ls asymmetrical in the two hemipenes: one with distal thumb-like expansion, the other without; tips of ls and ms in both hemipenes well separated; ls extending well beyond ms. Rpp with distal segment sub-triangular, rounded on dorsal margin, elongated and with narrow base. Lpp with proximal segment apically with small triangular outgrowth; distal segment sickle shaped, of equal length to proximal segment, distal half with parallel margins. Ratio for maximum length of Lpp distal segment to length of hemipenis ms distal margin 1:1.7. Ratio for maximum length Rpp distal segment to length of hemipenis ms distal margin approximately 1:1.3.

\section{Remarks and Etymology}

Two populations from the Paroo region of eastern Australia constitute a molecular lineage that is morphologically similar, but genetically distinct from B. cuensis Martens et al., 2012. Although some minor morphological differences have been found for Western Australian animals (provided in the description below), these do not appear to constitute reliable differences. Analysis of additional populations may enable the identification of more reliable diagnostic characters in the future. Therefore, this lineage is here not formally described as a different species from B. cuensis Martens et al., 2012.

Measurements (in $\mu \mathrm{m}$ )

ठ: $\mathrm{RV}: \mathrm{L}=1815-1863(n=2), \mathrm{H}=1043-1090(n=2) . \mathrm{LV}: \mathrm{L}=1955-1978(n=2), \mathrm{H}=1155-1165(n=2)$. Cp: $\mathrm{L}=1865-1892(n=5), \mathrm{W}=1000-1027(n=3), \mathrm{H}=1113-1123(n=2)$.

O): RV: $\mathrm{L}=2053-2113(n=2), \mathrm{H}=1198-1270(n=2) . \mathrm{LV}: \mathrm{L}=2200-2280(n=2), \mathrm{H}=1288-1335(n=2)$. $\mathrm{Cp}: \mathrm{L}=2055-2300(n=7), \mathrm{W}=1195-1265(n=5), \mathrm{H}=1218-1300(n=2)$.

\section{Localities investigated}

Unnamed pool, Kilcowera Station, south of Thargomindah QLD, coordinates: 28 40'13.2" S $143^{\circ} 54^{\prime} 10.4$ " E. Material used for the present illustration was collected on 14 Jun. 2011 by AK (Sample QLDP19A).

Island claypan, on Bloodwood Station, north west of Bourke NSW, collected 28 Sep. 2010 by Brian Timms, coordinates: $29^{\circ} 29^{\prime}$ S - 1444ำ E (Sample NSWB1).

\section{Material investigated}

§ from unnamed pool, Kilcowera Station QLD (W40052) and four $\widehat{\partial} \widehat{\jmath}$ from island claypan, Bloodwood Station NSW (W40001-W40004), with soft parts dissected in a sealed slide and valves stored dry in a micropalaeontological slide.

Two 9 ㅇ from island claypan, Bloodwood Station NSW (W40011-W40012), with soft parts dissected in a sealed slide and valves stored dry in a micropalaeontological slide.

ㅇ from unnamed pool, Kilcowera Station QLD (W40051), with soft parts dissected in a sealed slide and valves stored dry in a micropalaeontological slide. 


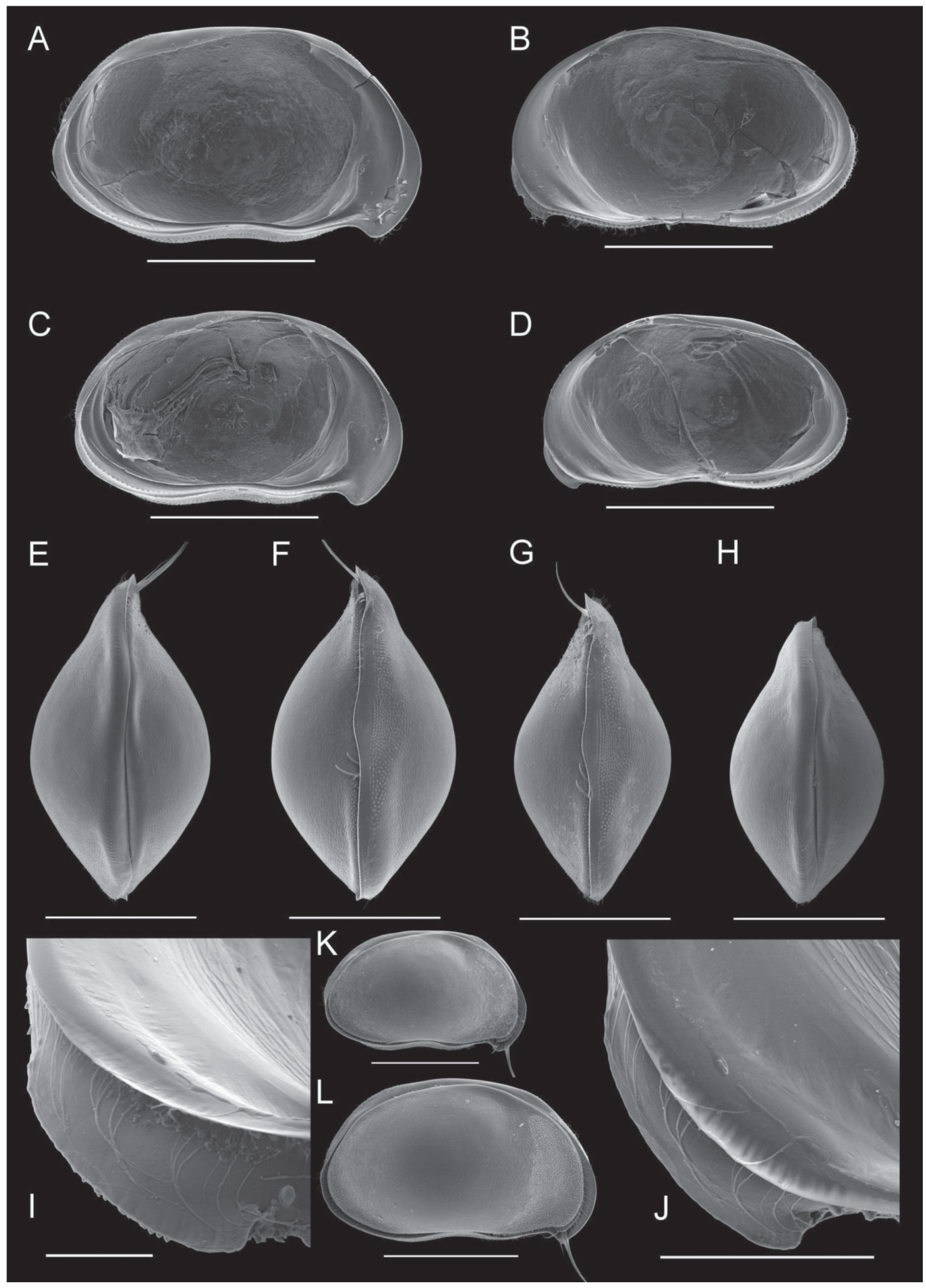

Fig. 12. Bennelongia cuensis sensu lato A-B, D-L from unnamed pool near Kilcowera Station, QLD; C from island claypan on Bloodwood Station NSW. A. +, LVi (W40053). B. +, RVi (W40053).

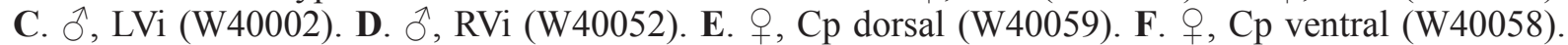

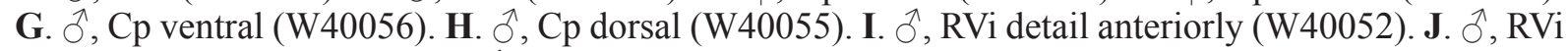

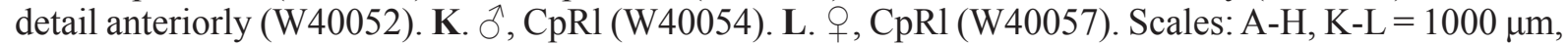
$\mathrm{J}=200 \mu \mathrm{m}, \mathrm{I}=100 \mu \mathrm{m}$. 
Three $\hat{\sigma}$ carapaces stored in a micropalaeontological slide (W40054-W40056), three $q$ carapaces stored in a micropalaeontological slide (W40057-W40059). ㅇ (W40053) with valves stored dry in a micropalaeontological slide, all from unnamed pool, Kilcowera Station QLD.

Three $\widehat{\partial}$ carapaces from island claypan, Bloodwood Station NSW (W40005-W40007), three $q$ carapaces stored in a micropalaeontological slide (W40008-W40011).

Several in toto specimens in EtOH, from unnamed pool, Kilcowera Station QLD (W40078).

Several in toto $q$ specimens in EtOH, from island claypan, Bloodwood Station NSW (W40079).

\section{Differential diagnosis}

The species belongs to the $B$. australis lineage due to its large size ( $\mathrm{L} \approx 1800 \mu \mathrm{m})$, the strong anterior rostrum in dorsal view and the presence of an anteroventral lapel on the RV. It can be distinguished from the other species in this lineage by the straight dorsal margin of the LV (less so in B. gwelupensis Martens et al., 2012 and B. coondinerensis Martens et al., 2012, the well separated tips of the 1s and the ms of both hemipenes (close in B. bidgelangensis Martens et al., 2012), the considerable overlap of the RV by the LV, sub-quadrate outline of the Cp in lateral view, the narrow lobes of the ms (limited overlap of RV by LV, rounded Cp outline and blunt ms lobes in B. lata Martens et al., 2012 and by the smaller Rpp to hemipenis ratio (maximum length of Rpp second segment to distal margin of $\mathrm{Hp} \mathrm{ms}$ approximately 1:1.3 in B. cuensis sensu lato, 1:2.2 in B. cuensis Martens et al., 2012).

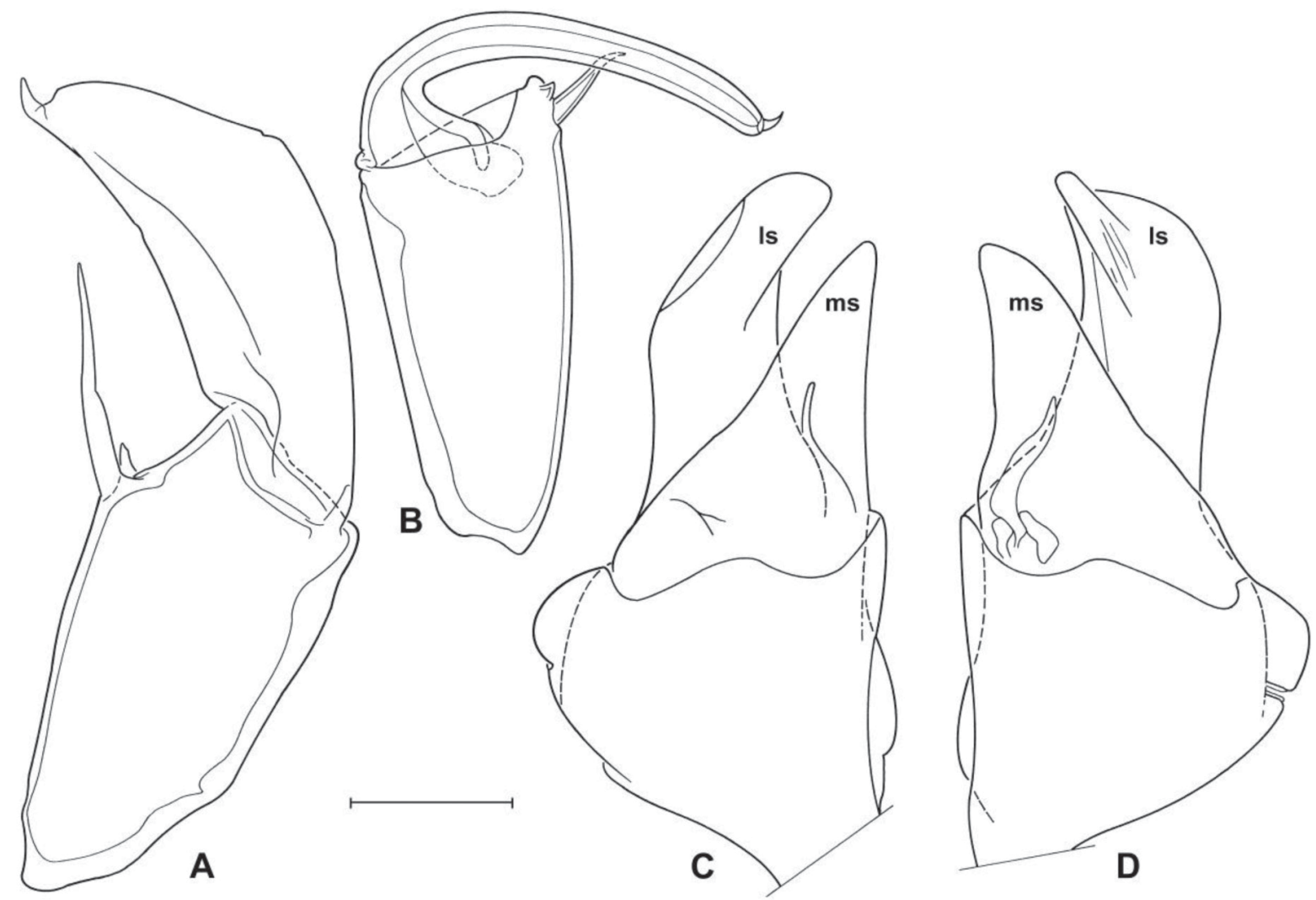

Fig. 13. Bennelongia cuensis sensu lato, all from unnamed pool near Kilcowera Station, QLD, $\widehat{o}$ (W40052). A. Right prehensile palp. B. Left prehensile palp. C. Hemipenis. D. Outline of other hemipenis. Scales: A-B $=89.3 \mu \mathrm{m}, \mathrm{C}-\mathrm{D}=104.2 \mu \mathrm{m}$. 


\section{Additional description}

Male and female carapaces (Fig. 12E-H, K-L) in right lateral view with straight dorsal margin, LV overlapping RV on all sides, particularly dorsally, greatest height situated throughout the middle third of the $\mathrm{Cp}$ length; greatest $\mathrm{Cp}$ width situated near the middle in dorsal and ventral view, anterior side with a rostrum and posterior side pointed; $\mathrm{Cp}$ surface set with short setae and weakly pitted. Male carapaces and valves slightly smaller than in the female, but with very similar shape.

Male and female LV (Fig. 12A, C) with straight dorsal margin, greatest height situated throughout the middle third of the valve length, anteroventral beak bluntly pointed.

Male and female RV (Fig. 12B, D) with greatest height situated slightly anterior of middle in lateral view, dorsal margin rounded; posterior selvage sub-marginal, inner list merging with selvage posteriorly; selvage expanded and striate at vicinity of anteroventral lapel (Fig. 12I-J); lapel mildly striate, broad and running parallel to selvage (Fig. 12I-J).

Most appendages as typical of the genus and without special features.

Rpp (Fig. 13A) with first segment length approximately 1.5 times its central width; subapically with two sensory organs, the proximal one long and slender, the distal one short; second palp segment nearly as long as the first one, with a narrow base and bluntly rounded dorsal margin, ratio for maximum length of second segment to length of hemipenis ms distal margin approximately $1: 1.3$, distally with small sensory organ.

Lpp (Fig. 13B) with first segment approximately two times its central width, subapically with one long proximally based and one short distally based sensory organ, apically with rounded outgrowth; second segment sickle shaped, equal in length to first segment, ratio for maximum length of second segment to length of hemipenis ms distal margin approximately 1:1.7, distal half straight with almost parallel margins, distally with small sensory organ.

Hemipenes (Fig. 13C-D) asymmetrical, one hemipenis with 1s distally bluntly pointed (Fig. 13C), the other with ls more sharply pointed with thumb-like expansion (Fig. 13D); bluntly pointed 1s of one hemipenis often folding at rounded dorsal margin suggesting the presence of a three dimensional structure; both hemipenes with ls and ms tips well separated, ls extending beyond ms, ms ventrally pointed and dorsally with rounded lobe.

\section{Ecology and distribution}

This cryptic lineage appears to have only a limited distribution near the Paroo region of south western Queensland and north western New South Wales. The species was found in high abundance in a turbid pool with grass and small aquatic weeds on Kilcowera Station.

\section{Discussion}

\section{Trends in Diversity and Radiation}

The $B$. barangaroo lineage now comprises at least the two morphotypes shown in the original description of B. barangaroo De Deckker, 1981 and the two new species described here (B. dedeckkeri sp. nov. and B. mckenziei sp. nov.). Thus, there are potentially four species within this lineage and currently they share a number of characters that obviously set them apart from the other lineages of Bennelongia. However, the high genetic distance between $B$. dedeckkeri sp. nov. and B. mckenziei sp. nov., and the morphological disparity of their diagnostic characters (anteroventral lapel on RV) suggest that if more 
recent radiations have occurred in this group, these species are likely to belong to diverse lineages of their own.

Considering 1) the genetic distance of $B$. regina sp. nov. to all other species, 2) the knowledge of at least one other species existing in the same lineage ( $B$. nimala), and 3$)$ the extensive radiation of other lineages in the genus ( $B$. australis lineage and $B$. pinpi lineage), it is likely that the $B$. nimala lineage consists of several more species. Further exploration of habitats throughout Australia is likely to yield more species.

\section{Cryptic diversity}

The discovery of cryptic lineages throughout all metazoan phyla (Beheregaray \& Caccone 2007; Pfenninger \& Schwenk 2007) is having profound implications for conservation and management (examples in Brown et al. 2007; Elmer et al. 2007; Fontaneto et al. 2008; Gustafsson et al. 2009; Marrone et al. 2010). Indeed, if genetic diversity is cryptic, it is difficult to see when it is becoming lost. A case in point is the baffling discovery of close to 40 reproductively isolated lineages ("species") within a single classical ostracod species, Eucypris virens (Bode et al. 2010). In some of the investigated ponds no less than 9 cryptic species occurred sympatrically (Bode et al. 2010). If one has to rely exclusively on morphological analyses, one could not deduce the fate of these cryptic species over time. Of further concern is that this is not an isolated case, as inland aquatic crustaceans appear to show high frequencies of cryptic diversity (Murphy et al. 2009; Witt et al. 2006) and the identification of the B. cuensis sensu lato cryptic lineage in the present study follows this notion.

\section{Morphological Characters}

Molecular methods allow stable, finer scale characters to be identified during the description of species that would otherwise have remained cryptic and unnoticed. Here, evidence for six genetically distinct groups within collections of Bennelongia in eastern Australia has been provided from phylogenetic (Maximum Likelihood and Bayesian Inference) and Parsimonious network analyses. $4 \mathrm{x}$ rule tests confirmed their identity as Evolutionary Genetic species following the arguments in Birky et al. (2010). These molecular methods were fundamental in the identification of the stable morphological character states defined for the three new species (B. dedeckkeri sp. nov., B. regina sp. nov and B. mckenziei sp. nov.), and in the identification of a truly cryptic lineage of a described species with no reliable morphological characters known at present (B. cuensis sensu lato).

The absence of both an anteroventral lapel and a bulbous expansion of the RV evident in B. mckenziei sp. nov. is a new character state not seen in this genus until now (absent from descriptions in De Deckker 1981, 1982; De Deckker \& McKenzie 1981; Martens et al. 2012). Both of these characters have the function of sealing the entrance of the LV sulcus when the valves are tightly closed (Martens et al. 2012). Thus the question arises of what this species uses when shutting the valves tightly, for example to survive a certain period of pond desiccation in a torpid state. It is possible that the anteroventral expansion of the selvage in $B$. mckenziei sp. nov. performs the same function.

The genetic clustering of $B$. pinpi De Deckker, 1981 with the other two species of the $B$. pinpi lineage confirmed the taxonomic significance of the bulbous expansion of the RV and the strongly produced anteroventral beak-like structure of the LV in the lineage diagnosis. Yet the position of B. pinpi De Deckker, 1981 as a separate clade in the phylogeny and as an unconnected cluster in the parsimonious network, together with the significant result of applying the $4 \mathrm{x}$ rule, strengthened the status of $B$. pinpi as a valid species. In the same way, the genetic identity and specific validity of $B$. harpago De Deckker \& McKenzie, 1981 has been shown. 


\section{The evolutionary origin of Bennelongia}

The Cyprididae Baird, 1845 are currently a dominant group that make up approximately half of all extant non-marine ostracods (Martens et al. 2008). During the Cretaceous, the Cypridea Bosquet, 1852 lineage was the dominant non-marine lineage and our current understanding is that it became extinct around the $\mathrm{K} / \mathrm{T}$ boundary. Cypridea had an internal marginal valve morphology (Horne \& Colin 2005) and beaklike feeding apparatus (Martens et al. 2012) which was somewhat similar to those in Bennelongia. For this reason it has been suggested that Bennelongia is not a member of Cyprididae, but in fact a surviving descendant of the ancient Cypridea lineage (Horne \& Martens 1998). If correct, this would also imply that the Cyprididae are not directly related to Cypridea. Instead, a small number of cypridid lineages may have coexisted with Cypridea and undergone an explosive radiation following the extinction of the Cypridea lineage (hypothesized in Martens et al. 2012).

Upon analysis of the results presented here, the presence of an anteroventral beak-like structure in all Bennelongia species indicates that this character is ancestral. The characters that function in sealing the sulcus however, originate from different structures in different lineages, suggesting that they have developed more recently. Moreover, two structures used for sealing the sulcus (modification of the outer list as a bulbous expansion and the expansion of the selvage) are congruent with molecular data, which show monophyly for these character states.

The existence of the three sulcus sealing character states provides a potentially interesting case of convergent evolution, whereby selection pressure for prevention of threats like desiccation and predation could have been applied after the development of the beak-like feeding apparatus. If Bennelongia is indeed a remnant of Cypridea, perhaps it was this pressure that drove selection for sulcus sealing character states and the extinction of the other Cypridea.

\section{Conclusion}

Speculation aside, the present paper reports on six species of Bennelongia from eastern Australia, divided over five different lineages within the genus. The validity of two existing species ( $B$. pinpi De Deckker, 1981 and B. harpago De Deckker \& McKenzie, 1981) was confirmed. Three species were formally described as new (B. dedeckkeri sp. nov., B. mckenziei sp. nov. and B. regina sp. nov.). The final taxon was a true cryptic species (B. cuensis sensu lato) that was established with molecular methods, but could not be identified based on morphology and therefore is not formally described here.

\section{Acknowledgements}

This research was funded by an ABRS grant (nr RF211-33: 'Biodiversity and taxonomy of Ostracoda (Crustacea) from temporary water bodies of inland Western Australia'), an Edith Cowan University Industry Collaboration grant and Edith Cowan University - School of Natural Sciences postgraduate funding. We acknowledge land owners who allowed us to sample sites on Lake Dunn station, Hazelmere Station, Kilcowera Station and at Lake Powlathanga. Bryan Davies assisted with collections. Julien Cilis (RBINSc, Brussels, Belgium) assisted with SEM micrographs. Claudine Behen (RBINSc, Brussels, Belgium) inked the line drawings. Sequencing was performed at the Australian Genome Research Facility (Perth) and at the RBINSc with assistance from Zohra Elouaazizi (RBINSc, Brussels, Belgium). Mike Scanlon (Bennelongia Pty Ltd, Perth, WA) produced the map in Fig. 1. We thank Céline Poux for designing the alternative COI primers. We also thank Colleen Hayward (Kurongkurl Katitjin, Edith Cowan University) for her advice in changing some preliminary species names.

\section{References}

Altschul S.F., Gish W., Miller W., Myers E.W. \& Lipman D.J. 1990. Basic local alignment search tool. Journal of Molecular Biology 215: 403-410. http://dx.doi.org/10.1006/jmbi.1990.9999 
Beheregaray L. \& Caccone A. 2007. Cryptic biodiversity in a changing world. Journal of Biology 6: 1-5. http://dx.doi.org/10.1186/jbiol60

Birky C.W., Adams J., Gemmel M. \& Perry J. 2010. Using population genetic theory and DNA sequences for species detection and identification in asexual organisms. PLOS ONE 5 (5): e10609. http://dx.doi. org/10.1371/journal.pone.0010609

Birky C.W. \& Barraclough T.G. 2009. Asexual Speciation. In: Schön I., Martens K. \& van Dijk P. (eds), Lost Sex, The Evolutionary Biology of Parthenogenesis: 201-216. Springer: Dordrecht, Heidelberg, London, New York.

Bode S.N.S., Adolfsson S., Lamatsch D.K., Martins M.J.F., Schmit O., Vandekerkhove J., Mezquita F., Namiotko T., Rossetti G., Schön I., Butlin R.K. \& Martens K. 2010. Exceptional cryptic diversity and multiple origins of parthenogenesis in a freshwater ostracod. Molecular Phylogenetics and Evolution 54: 542-552. http://dx.doi.org/10.1016/j.ympev.2009.08.022

Brown D., Brenneman R., Koepfli K.-P., Pollinger J., Mila B., Georgiadis N., Louis E., Grether G., Jacobs D. \& Wayne R. 2007. Extensive population genetic structure in the giraffe. BMC Biology 5: 57. http://dx.doi.org/10.1186/1741-7007-5-57

Clement M., Posada D. \& Crandall K.A. 2000. TCS: a computer program to estimate gene genealogies. Molecular Ecology 9: 1657-1659. http://dx.doi.org/10.1046/j.1365-294x.2000.01020.x

Cook B.D., Baker A.M., Page T.J., Grant S.C., Fawcett J.H., Hurwood D.A. \& Hughes J.M. 2006. Biogeographic history of an Australian freshwater shrimp, Paratya australiensis (Atyidae): the role life history transition in phylogeographic diversification. Molecular Ecology 15: 1083-1093. http://dx.doi. org/10.1111/j.1365-294X.2006.02852.x

De Deckker P. 1981. Taxonomy and ecological notes of some ostracods from Australian inland waters. Transactions of the Royal Society of South Australia 105: 91 - 138.

De Deckker P. 1982. On Bennelongia tunta De Deckker. A Stereo Atlas of Ostracod Shells 9: 117-124.

De Deckker P. \& McKenzie K.G. 1981. Bennelongia, a new Cypridid ostracod genus from Australasia. Transactions of the Royal Society of South Australia 105: 53-58.

Elmer K., Davila J. \& Lougheed S. 2007. Cryptic diversity and deep divergence in an upper Amazonian leaflitter frog, Eleutherodactylus ockendeni. BMC Evolutionary Biology 7: 247. http://dx.doi. org/10.1186/1471-2148-7-247

Folmer O., Black M., Hoeh W., Lutz R. \& Vrijenhoek R. 1994. DNA primers for amplication of mitochondrial cytochrome $\mathrm{C}$ oxidase subunit I from diverse metazoan invertebrates. Molecular Marine Biology and Biotechnology 3: 294-299.

Fontaneto D., Boschetti C. \& Ricci C. 2008. Cryptic diversification in ancient asexuals: evidence from the bdelloid rotifer Philodina flaviceps. Journal of Evolutionary Biology 21: 580-587. http://dx.doi. org/10.1111/j.1420-9101.2007.01472.x

Geospiza Inc. (n.d.). FinchTV (Version 1.4.0). Seattle, WA, USA.

Guindon S. \& Gascuel O. 2003. A simple, fast, and accurate algorithm to estimate large phylogenies by maximum likelihood. Systematic Biology 52: 696-704. http://dx.doi.org/10.1080/10635150390235520

Gustafsson D.R., Price D.A. \& Erseus C. 2009. Genetic variation in the popular lab worm Lumbriculus variegatus (Annelida:Clitellata: Lumbriculidae) reveals cryptic speciation. Molecular Phylogenetics and Evolution 51: 182-189. http://dx.doi.org/10.1016/j.ympev.2008.12.016

Hart M.W. \& Sunday J. 2007. Things fall apart: biological species form unconnected parsimony networks. Biological Letters 3: 509-512. http://dx.doi.org/10.1098/rsbl.2007.0307 
Hasegawa M., Kishino H. \& Yano T. 1985. Dating the human-ape split by a molecular clock of mitochondrial DNA. Journal of Molecular Evolution 22: 160-174. http://dx.doi.org/10.1007/ BF02101694

Horne D.J. \& Colin J. P. 2005. The affinities of the ostracod genus Cypridea Bosquet, 1852, and its allies, with consideration of implications for the phylogeny of non-marine cypridoidean ostracods. Revue de Micropaléontologie 48: 25-35. http://dx.doi.org/10.1016/j.revmic.2004.12.003

Horne D.J. \& Martens K. 1998. An assessment of the importance of resting eggs for the evolutionary success of non-marine Ostracoda (Crustacea). In: Brendonck L., Meester L.D. \& Hairston N. (eds), Evolutionary and ecological aspects of crustacean diapause. Advances in Limnology: 549-561.

Huelsenbeck J.P. \& Ronquist F. 2001. MRBAYES: Bayesian inference of phylogenetic trees. Bioinformatics 17: 754-755. http://dx.doi.org/10.1093/bioinformatics/17.8.754

Karanovic I. 2007. Candoninae (Ostracoda) from the Pilbara region in Western Australia. Crustaceana Monographs 7: 432. http://dx.doi.org/10.1163/ej.9789004156937.i-434

Karanovic T. 2004. Subterranean Copepoda from arid Western Australia. Brill, Leiden.

Kimball S., Mattis P. \& Team G.D. (1995). GIMP (GNU Image Manipulation Software), (Version 2.6.11). Free Software Foundation Inc, Boston, MA.

Kimura M. 1981. Estimation of evolutionary distances between homologous nucleotide sequences. Proceedings of the National Academy of Sciences, U.S.A. 78: 454-458. http://dx.doi.org/10.1073/ pnas.78.1.454

Koenders A., Martens K., Halse S. \& Schön I. 2012. Cryptic species of the Eucypris virens species complex (Ostracoda, Crustacea) from Europe have invaded Western Australia. Biological Invasions 14: 2187-2201. http://dx.doi.org/10.1007/s10530-012-0224-y

Larkin M.A., Blackshields G., Brown N.P., Chenna R., McGettigan P.A., McWilliam H., Valentin F., Wallace I.M., Wilm A., Lopez R., Thompson J.D., Gibson T.J. \& Higgins D.G. 2007. Clustal W and Clustal X version 2.0. Bioinformatics 23: 2947-2948. http://dx.doi.org/10.1093/bioinformatics/btm404

Marrone F., Lo Brutto S. \& Arculeo M. 2010. Molecular evidence for the presence of cryptic evolutionary lineages in the freshwater copepod genus Hemidiaptomus G.O. Sars, 1903 (Calanoida, Diaptomidae). Hydrobiologia 644: 115-125. http://dx.doi.org/10.1007/s10750-010-0101-6

Martens K., Halse S. \& Schön I. 2012. Nine new species of Bennelongia De Deckker \& McKenzie, 1981 (Crustacea, Ostracoda) from Western Australia, with the description of a new subfamily. European Journal of Taxonomy 8: 1-56. http://dx.doi.org/10.5852/ejt.2012.8

Martens K., Schön I., Meisch C. \& Horne D. 2008. Global diversity of ostracods (Ostracoda, Crustacea) in freshwater. Hydrobiologia 595: 185-193. http://dx.doi.org/10.1007/s10750-007-9245-4

Murphy N.P., Adams M. \& Austin A.D. 2009. Independent colonization and extensive cryptic speciation of freshwater amphipods in the isolated groundwater springs of Australia's Great Artesian Basin. Molecular Ecology 18: 109-122. http://dx.doi.org/10.1111/j.1365-294X.2008.04007.x

Pfenninger M. \& Schwenk K. 2007. Cryptic animal species are homogeneously distributed among taxa and biogeographical regions. BMC Evolutionary Biology 7: 1-6. http://dx.doi.org/10.1186/1471-2148$\underline{7-121}$

Posada D. 2008. jModelTest: Phylogenetic model averaging. Molecular Biology and Evolution 25: 1253-1256. http://dx.doi.org/10.1093/molbev/msn083 
Schön I., Pinto R.L., Halse S., Smith A.J., Martens K. \& Birky C.W.jr. 2012. Cryptic species in putative ancient asexual darwinulids (Crustacea, Ostracoda). PLOS ONE 7: e39844. http://dx.doi.org/10.1371/ journal.pone.0039844

Tamura K., Peterson D., Peterson N., Stecher G., Nei M. \& Kumar S. 2011. MEGA5: Molecular evolutionary genetics analysis using maximum likelihood, evolutionary distance, and maximum parsimony methods. Molecular Biology and Evolution 28: 2731-2739. http://dx.doi.org/10.1093/ $\underline{\text { molbev/msr121 }}$

Timms B.V. 2012. An appraisal of the diversity and distribution of large branchiopods (Branchiopoda: Anostraca, Laevicaudata, Spinicaudata, Cyclestherida, Notostraca) in Australia. Journal of Crustacean Biology 32: 615-623. http://dx.doi.org/10.1163/193724012X634198

Timms B.V. \& Sanders P.R. 2002. Biogeography and ecology of Anostraca (Crustacea) in middle Paroo catchment of the Australian arid-zone. Hydrobiologia 486: 225-238. http://dx.doi. org/10.1023/A:1021363104870

Väinölä R., Witt J., Grabowski M., Bradbury J., Jazdzewski K. \& Sket B. 2008. Global diversity of amphipods (Amphipoda; Crustacea) in freshwater. Hydrobiologia 595: 241-255. http://dx.doi. org/10.1007/s10750-007-9020-6

Witt J.D.S., Threloff D.L. \& Hebert P.D.N. 2006. DNA barcoding reveals extraordinary cryptic diversity in an amphipod genus: implications for desert spring conservation. Molecular Ecology 15: 3073-3082. http://dx.doi.org/10.1111/j.1365-294X.2006.02999.x

Manuscript received: 16 July 2012

Manuscript accepted: 9 October 2012

Published on: 15 October 2012

Topic editor: Rudy Jocqué

In compliance with the $I C Z N$, printed versions of all papers are deposited in the libraries of the institutes that are members of the EJT consortium: Muséum National d'Histoire Naturelle, Paris, France; National Botanic Garden of Belgium, Meise, Belgium; Royal Museum for Central Africa, Tervuren, Belgium; Natural History Museum, London, United Kingdom; Royal Belgian Institute of Natural Sciences, Brussels, Belgium; Natural History Museum of Denmark, Copenhagen, Denmark. 